\title{
Correlations Between Morphology and Electrophysiology of Pyramidal Neurons in Slices of Rat Visual Cortex. II. Electrophysiology
}

\author{
Adrian Mason and Alan Larkman \\ University Laboratory of Physiology, Oxford, OX1 3PT England
}

\begin{abstract}
The aim of this study was to determine whether the different morphological classes of pyramidal neurons in layers $2 / 3$ and 5 of rat visual cortex (Larkman and Mason, 1990) have particular electrophysiological properties. Neurons in in vitro slices of rat visual cortex were impaled with glass micropipettes containing horseradish peroxidase (HRP) and studied using current-clamp techniques prior to pressure injection of HRP into the neurons. On morphological grounds, cells stained in layer $2 / 3$ were placed into a single class whereas layer 5 cells were divided into 2 classes. Cells in one of these classes had thick apical dendrites which arborized in layer 1 , whereas the apical dendrites of cells in the other class were thinner and did not reach layer 1 (Larkman and Mason, 1990). Despite variation between individual cells of a single class, significant differences were found in the time constants, current/voltage relations, and repetitive firing behaviors of the 3 classes. Burst firing responses to injected current pulses were confined to the layer 5 cells with thick apical dendrites. These results add to those from other areas of the brain demonstrating that the electrophysiological properties of pyramidal neurons are heterogeneous. Furthermore, we have shown that distinctive intrinsic membrane properties of pyramidal neurons in visual cortex are correlated with different morphologies.
\end{abstract}

Neurons may be characterized by a variety of features, such as their projection targets, dendritic morphology, electrophysiological properties, and the identity of their neurotransmitters. Knowledge of how these different aspects of neuronal phenotype are related is important for understanding neuronal function. We are interested in possible associations between morphology and electrophysiological properties of neurons in the visual cortex. In the visual cortex, as in other neocortical areas, most neurons are pyramidal (Peters, 1987). The visual responses of neurons in the visual cortex have been studied intensively (see Peters and Jones, 1985; Rose and Dobson, 1985), and descriptions of somadendritic and axonal morphology have been obtained for some neurons with known receptive field properties

\footnotetext{
Received June 14, 1989: revised Oct. 2, 1989; accepted Nov. 13.1989

This work was supported by The Wellcome Trust (grant 15932/1.5) and the Medical Research Council (grant PG7900491). A.L. is a Beit Memorial Research Fellow. We are grateful to Guy Major for computer programming and Sarah Bacon for help in preparing the illustrations. We thank Colin Blakemore, Michael Häusser. Julian Jack. and Guy Major for helpful comments on the manuscript.

Correspondence should be addressed in Dr. Adrian Mason. I Iniversity Department of Pharmacology, South Parks Road. Oxford OXI 3QT. England.

(opyright : 1990 Society for Neuroscience $0270-6474 / 90 / 051415-14 \$ 02.00 / 0$
}

(Gilbert and Wiesel, 1979: Parnavelas et al.. 1983; Martin and Whitteridge, 1984). However, possible correlations between the morphology and intrinsic membrane properties of neurons in the visual cortex remain largely unexplored. In studies of cat and monkey cortex in vivo, subtypes of pyramidal tract cells have been shown to possess distinct electrophysiological and morphological properties (Calvin and Sypert. 1976; Deschênes et al., 1979: Hamada et al.. 1981). However, although McCormick et al. (1985) were able to divide pyramidal cells of guinea pig sensorimotor cortex in vitro into 2 classes on the basis of spike firing pattern ("regular-spiking" and "bursting"), they could not detect differences in their morphology.

Using intracellular recording combined with intracellular staining of the same neurons, we have investigated the morphology and electrophysiology of pyramidal neurons in layers $2 / 3$ and 5 of slices from rat visual cortex. This paper presents electrophysiological data from neurons whose morphology was described in the previous paper (Larkman and Mason, 1990).

\section{Materials and Methods}

Details of slice preparation and maintenance. manufacture of micropipettes, and techniques of neuronal impalement have been given previously (Larkman et al., 1988: Larkman and Mason. 1990). Only cells that had stable resting potentials more negative than $65 \mathrm{mV}$, action potential thresholds greater than $10 \mathrm{mV}$ positive to rest, and action potentials whose peaks overshot zero potential were accepted for detailed electrophysiological study. The quantitative results presented in this report are based on 47 cells in layers $2 / 3$ and 5 which met these criteria and which were also injected with HRP. In addition, we recorded some data from (and injected HRP into) 6 cells that required continuous hyperpolarizing current injection in order for the impalement to be maintained. These cells were used only for correlations between morphological cell type and qualitative electrophysiological results. Neurons were divided into 3 classes: layer $2 / 3$ (L2/3) cells, slender layer 5 (slender L5) cells. and thick layer 5 (thick L5) cells, according to the morphological criteria described in the previous paper (Larkman and Mason. 1990).

Intracellular recording and data anal.sis. Conventional bridge-balance techniques were employed to allow current injection and voltage recording with a single micropipette. Micropipettes showed time-dependent changes in resistance when passing currents greater than about $0.5 \mathrm{nA}$, so procedures requiring measurement of intracellular potential during current injection were limited to applied currents less than this value. Furthermore, passage of large currents tended to prevent the subsequent ejection of HRP. Signals from the micropipette amplifier (WPI 707) were recorded on tape (Racal Store 4DS) with a bandwidth of $0-5 \mathrm{kHz}( \pm 0.5 \mathrm{~dB})$. The recordings were digitized and measured using a combination of microcomputer (IBM PC AT) and interface (Cambridge Electronic Design 1401). Signal averaging was employed when appropriate. Recordings from some early experiments were digitized, averaged and measured using a digital nscilloscope (Crould 14?5)

Resting potential was recorded relative to the potential recorded extracellularly prior to impalement. Membrane time constant was mea- 
Table 1. Subthreshold membrane properties

\begin{tabular}{|c|c|c|c|}
\hline & $\mathrm{L} 2 / 3$ & Slender L5 & Thick L5 \\
\hline Resting potential (mV) & $-75 \pm 5(22)^{*}$ & $-71 \pm 5$ & $-71 \pm 5 \quad(15)$ \\
\hline Time constant (msec) & $12.0 \pm 3.0(22)$ & $19.5 \pm 4.0(10)^{*}$ & $10.4 \pm 2.7(13)$ \\
\hline$R_{\mathrm{in}}(\mathrm{ss})(\mathrm{M} \Omega)^{a}$ & $37 \pm 9(22)^{* * *}$ & $61 \pm 26(10)^{* * *}$ & $18 \pm 10(14)^{* * *}$ \\
\hline$\%$ sag $(\text { hyp) })^{b}$ & $0.4 \pm 0.9(22)^{* * *}$ & $8.5 \pm 6.4(10)^{* * *}$ & $22.0 \pm 7.3(14)^{* * *}$ \\
\hline$\%$ sag (dep) & $0.5 \pm 1.6(18)^{* * *}$ & $5.5 \pm 5.5(10)^{* * *}$ & $21.8 \pm 7.8(14)^{* * *}$ \\
\hline$\%$ overshoot $^{d}$ & $1.0 \pm 1.7(22)^{* * *}$ & $12.6 \pm 8.5(10)^{* * *}$ & $23.6 \pm 8.1(14)^{* * *}$ \\
\hline$\%$ undershoot & $1.3 \pm 2.5(18)^{* * *}$ & $10.9 \pm 6.8(10)^{* * *}$ & $19.1 \pm 4.6(14)^{* * * *}$ \\
\hline
\end{tabular}

Data presented in this and subsequent tables are given as mean \pm SD $(n)$. Significant differences between cell classes (at $p \leq 0.05$ ) are indicated as follows: ${ }^{*}=$ difference between this class and both of the others; ${ }^{* *}=$ difference only between these two classes; ${ }^{* * *}=$ difference between all 3 classes.

"Apparent steady-state input resistance calculated from the slope of the current/voltage relationship over the region 5$10 \mathrm{mV}$ negative to rest

"Percentage sag during hyperpolarizing pulses $\left\{100 \times\left(V_{\text {peak }}-V_{\text {stady statc }}\right) / V_{\text {peak }}\right\}$ (Stafstrom et al., 1984b). For any given cell, the percentage sag was reasonably independent of the size of the peak voltage deflection. Thus, for each cell, we averaged the percentage sag from all the different strengths of hyperpolarizing current pulses.

"As above, but for depolarizing pulses. "Hyp" and "dep" in parentheses after "\% sag" refer to the sag occurring during hyperpolarizing or depolarizing current pulses (respectively), not to the direction of the sag phenomenon itself.

"Percentage overshoot after hyperpolarizing pulses, i.e., the amount by which the membrane potential became transiently more positive than resting potential after a hyperpolarizing pulse, expressed as a percentage of the peak voltage deviation during the pulse $\left\{100 \times V_{\text {overshoot }} / V_{\text {peak }}\right\}$. The percentage overshoot was relatively constant regardless of the size of the current pulsc, so for each neuron we averaged the values from all the different strengths of hyperpolarizing pulses.

"As above, but refers to the transient negativity following depolarizing current pulses.

sured using brief, hyperpolarizing current pulses (Iansek and Redman, 1973). The voltage responses to about 60 , approximately $0.5 \mathrm{msec}$ long, hyperpolarizing pulses of $0.75-2.5 \mathrm{nA}$, delivered at $1 \mathrm{~Hz}$, were averaged. Current/voltage relationship was investigated using current pulses of 100-150 msec duration, delivered at $1 \mathrm{~Hz}$. For most cells, about 20 sweeps were averaged for each current strength.

Suprathreshold properties were investigated using current pulses of approximately $400 \mathrm{msec}$ duration. Action potential measurements were taken from the first (usually the only) spike evoked by a just suprathreshold pulse. For each cell, 2 or 3 sweeps were analyzed and the average values determined. Spike afterpotentials were also investigated with just suprathreshold pulses, but the measurements were made from an averaged waveform of several sweeps, aligned on spike threshold. Spike frequency/current relationships and spike frequency adaptation were determined using 400-msec current pulses, delivered at $0.2 \mathrm{~Hz}$. Some cells were stimulated orthodromically by single shocks delivered via a bipolar, nichrome electrode placed on the gray matter or underlying white matter.

Statistical analysis. Although descriptive statistics are given as mean $\pm \mathrm{SD}(\mathrm{n})$, further analysis employed methods not requiring the assumption that the data were normally distributed. The Mann-Whitney $U$-test was used for comparing cell classes, and the Kendall coefficient of rank correlation (tau) was used to test for correlations in the data. All significance levels are for 2-tailed tests.

\section{Results}

\section{Subthreshold properties}

Resting potential. The resting potential of $\mathrm{L} 5$ neurons was slightly less negative than that of $\mathrm{L} 2 / 3$ neurons (Table 1 ).

Time constant. For L2/3 cells, the entire later part of the voltage decay following a hyperpolarizing current pulse appeared to conform to a single exponential (Fig. $1 A$ ). The voltage decay for L5 cells gradually became more rapid than expected from single exponential decay (Fig. 1, B, C), the effect being particularly pronounced for thick L5 cells. In 3 of 10 slender L5 cells, and 13 of 14 thick L5 cells, the membrane potential transiently "overshot" the resting level following the current pulse. A straight line was selectively fitted to a region of the semilog plot by least-squares linear regression, and the membrane time constant was taken from the slope of this line. The region was chosen (by eye) to exclude the early, faster decay, which represents redistribution of charge over the neuron (Rall, 1969). In the case of L5 cells, we also excluded the later part of the plot that deviated from exponential decay. The mean time constant of the slender L5 cells was greater than those of the other 2 cell classes (Table 1).

Current/voltage relationship. All neurons showed a decrease in apparent input resistance $\left(R_{\text {in }}\right)$ with increasing strength of hyperpolarizing pulses (Fig. 2). We measured $R_{\text {in }}$ from the I/V slope over the range just negative to rest. Thick L5 neurons had the lowest $R_{\text {in }}$ values and slender L 5 neurons the highest. L2/3 cell values were intermediate (Table 1). For 40 of the 42 neurons tested, $R_{\text {in }}$ measured with depolarizing pulses was greater than that measured with hyperpolarizing pulses. The $R_{\text {in }}$ of the remaining 2 cells was approximately constant regardless of the polarity of the current pulse used to measure it.

During both depolarizing and hyperpolarizing current pulses, the membrane potential of L5 neurons tended to "sag" back toward resting potential (Fig. 2, Bl, Cl). There was a positive correlation among $\mathrm{L} 5$ cells between the amount of sag during hyperpolarizing pulses and that during depolarizing pulses (tau $=0.74, p<0.001)$. On average, thick L5 neurons showed more sag than slender L5 neurons (Table 1). At the end of the pulse the membrane potential of L5 neurons tended to "overshoot" (after hyperpolarizing pulses) or "undershoot" (after depolarizing pulses) the resting level (Fig. 2, Bl, CI). The overshoot did not trigger action potentials, although it is possible that larger, or longer, current pulses would have done so (LopezBarneo and Llinás, 1988). There was a positive correlation between the percentage sag (see Table 1 legend) during depolarizing or hyperpolarizing current pulses and the percentage undershoot or overshoot (respectively) that occurred after the end of the pulses (depolarizing pulses: tau $=0.72, p<0.001$; hyperpolarizing pulses: tau $=0.85, p<0.001$ ). Thick L5 cells showed greater undershoot and overshoot than slender L5 cells (Table 1).

Most L2/3 cells showed no detectable sag, overshoot, or undershoot in response to small current pulses (Fig. 2Al). In the 
few $L 2 / 3$ cells in which these effects were present, they were much less pronounced than in L5 neurons.

\section{Suprathreshold properties}

Action potential. All neurons had qualitatively similar action potential shapes (Fig. 3, Table 2, but see below for burst firing of thick L5 cells). Spike thresholds of both classes of L5 neuron were closer to resting potential than those of $\mathrm{L} 2 / 3$ cells. However, because $L 5$ cells had less negative resting potentials than L2/3 cells, absolute spike thresholds were similar for all neurons. The action potentials of all neurons had rates of rise several times greater than their rates of fall, although the rate of rise was somewhat less for slender L5 cells than for the other 2 classes. Thick L5 neurons had considerably faster falling phases, which led to a smaller value for the ratio of rise-rate to fall-rate for this cell class. The greater rate of repolarization was also largely responsible for the narrower spikes of the thick L5 neurons.

Spike afterpotentials. Single action potentials in neurons of all 3 classes were followed by the same sequence of afterpotentials (Fig. 3), although the prominence of each afterpotential varied considerably, even between cells of the same class. An initial afterhyperpolarization (fast AHP), appearing as a continuation of the spike repolarization, was followed by a depolarizing afterpotential (DAP) and then by a slower after-hyperpolarization (slow AHP). Slender L5 neurons had the largest slow AHPs and the longest times-to-peak for all 3 afterpotentials (Table 3 ). Of the 3 cell types, the DAPs of thick $\mathrm{L} 5$ cells reached a potential level closest to spike threshold.

Burst firing. The most striking electrophysiological property of thick L 5 cells was their ability to fire bursts of action potentials in response to depolarizing current pulses (Fig. 4). A typical burst consisted of a large, brief spike followed by a number of broader, decrementing spikes riding on a wave of depolarization and followed by a pronounced hyperpolarization. Such bursts were never seen in L2/3 or slender L5 neurons.

About two-thirds of the thick L5 cells showed bursts in response to current pulses that were just above spike threshold. In some of these cells the burst pattern remained constant when the current strength was increased, whereas in other cells the burst pattern changed (Fig. 5A). The remaining one-third of thick L5 cells fired single spikes in response to just suprathreshold pulses and showed bursting behavior only when the current was increased. This change to burst firing was often gradual, with the burst pattern becoming progressively more pronounced as the current was increased (Fig. $5 B$ ). Some thick L5 neurons fired 2 bursts during just suprathreshold current pulses of 400 msec duration. However, in response to stronger currents, these cells, like other thick L5 cells, fired only one burst followed by a train of single spikes.

In 5 of 6 thick L5 cells tested, extracellular stimulation of the white or gray matter evoked bursts similar to those produced by intracellular current injection (Fig. 6). In the remaining cell extracellular stimulation evoked only single spikes, even though bursts could be elicited by intracellular current injection.

Repetitive firing. During current pulses just above threshold, both L2/3 and slender L5 cells fired 1 or 2, widely separated spikes (Fig. 7, $A 1, B I$ ). Two-thirds of the thick L5 cells fired a burst at the beginning of the pulse and, in some cases, a second burst later in the pulse (Fig. $7 \mathrm{Cl}$ ). As the current strength was increased, all cells produced an increasing number of spikes. Most L2/3 cells showed a strong tendency to fire a pair of spikes
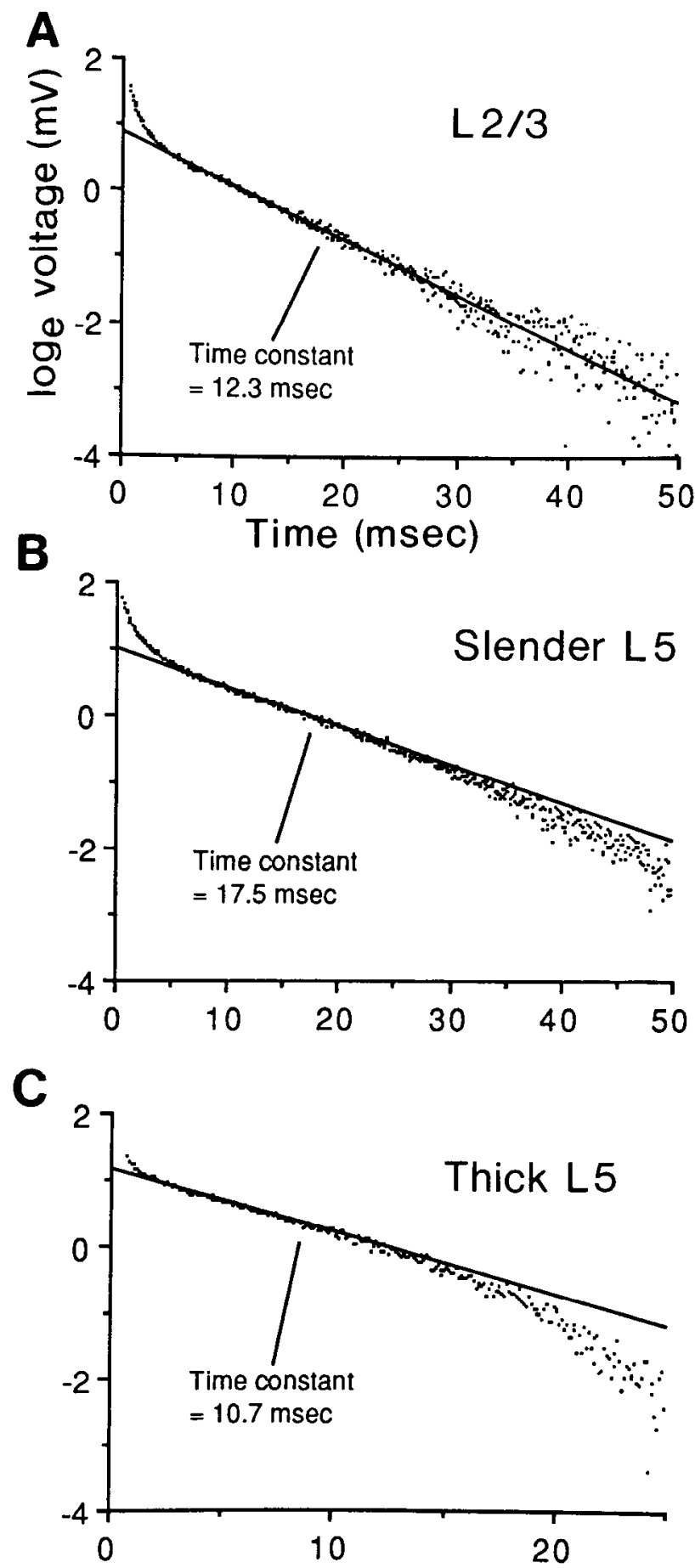

Figure 1. Membrane time constant. Semilogarithmic plots of the voltage decay following a brief $(0.5 \mathrm{msec})$, hyperpolarizing current pulse for an $\mathrm{L} 2 / 3$ cell $(A)$, a slender $\mathrm{L} 5$ cell $(B)$, and a thick $\mathrm{L} 5$ cell $(C)$. Axis labels apply to all 3 graphs. Zero on the abscissa corresponds to the end of the current pulse. The solid lines (from which the time constants were taken) are least-squares fits to straight-line portions of the plots. Note the different time scale in $C$.

at the beginning of the pulse. In some L $2 / 3$ cells, as the current was increased further, additional spikes seemed to be abruptly "recruited" to the initial phase of high-frequency firing. Slender L5 cells showed a more gradual increase in spike frequency for the first few intervals as the current strength was increased, although there was considerable variation in the behavior of 
$L 2 / 3$
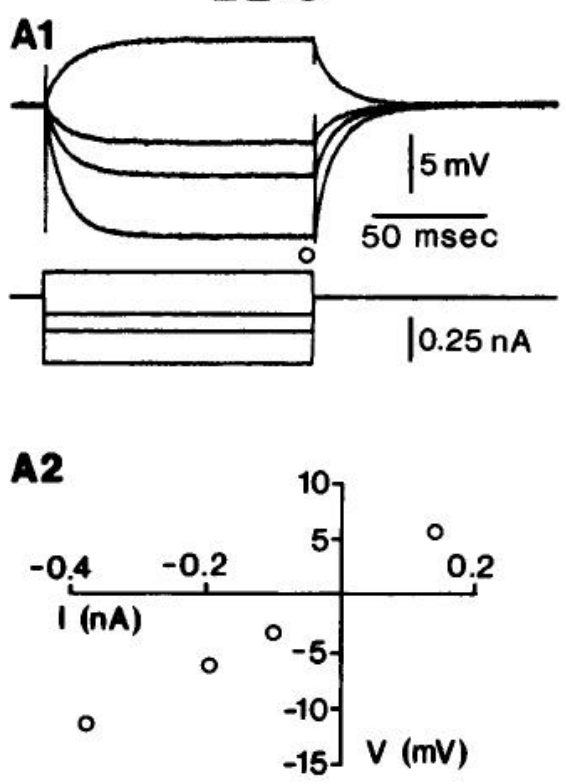

Slender L5

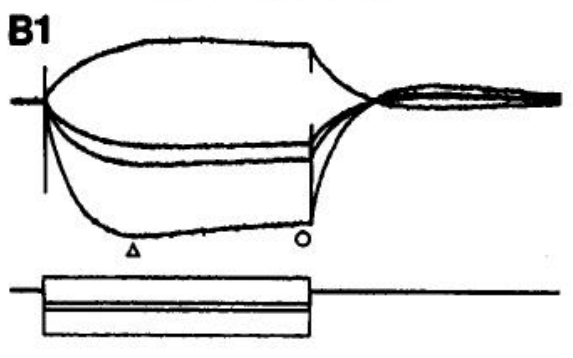

B2

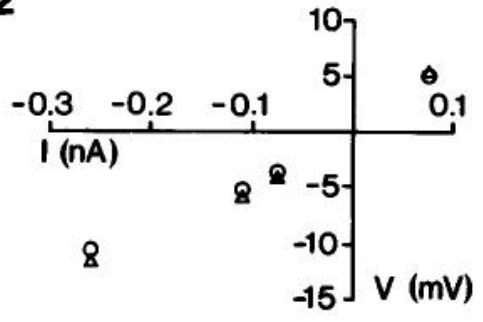

Thick L5

C1
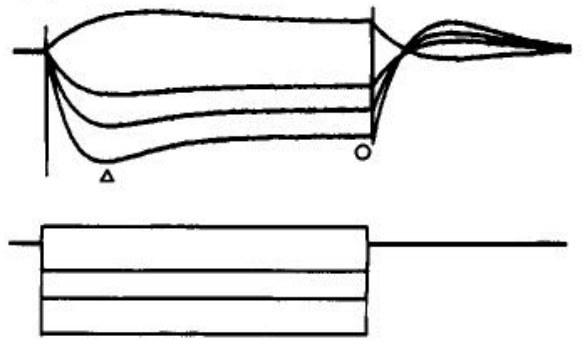

C2

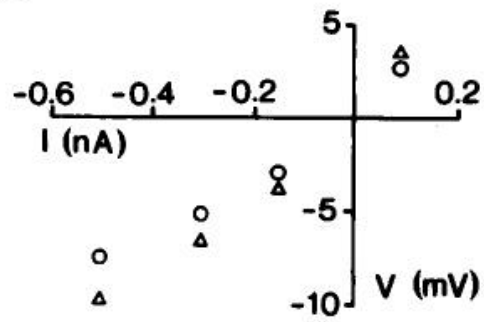

Figure 2. Current/voltage relationships. A1, BI, C1, Voltage responses (upper traces) to injected current (lower traces) for an L2/3 cell (A1), a slender L5 cell $(B I)$, and a thick L5 cell $(C 1)$. Calibrations apply to all 3 panels. The voltage response was measured at its peak (triangles) and just before the end of the current pulse (circles), and both values were plotted against injected current $(A 2, B 2, C 2)$.

individual cells. In thick L5 cells, the initial burst was followed by single spikes whose frequency increased with increasing current (Fig. 7, C2, C3).

Spike frequency/current relationship $(f / I)$. We used data of the kind shown in Figure 7 to quantify the relationship between instantaneous spike frequency (the reciprocal of the interspike interval) and the magnitude of injected current for the first 3 intervals (f1, f2, f3) and for steady-state firing (fss) at the end of the pulse. With the exception of fss, we did not perform this analysis for thick L5 cells, because of the existence of bursts. Figure 8 shows an example of $\mathrm{f} 1, \mathrm{f} 2$, and $\mathrm{f} 3$ plotted against injected current for an L2/3 cell. For both L2/3 and slender L5 cells the relationship between $\mathrm{fl}$ and injected current (f1/I) usually had at least 2 distinct regions, with an initial shallow slope being followed by a much steeper slope. The initial slope existed over only a small range of injected current and could not be detected in 9 of the $26 \mathrm{~L} 2 / 3$ and slender L5 cells analyzed. In 23 of the 26 cells the slope of the second region began to level off at higher current strengths, resulting in an " $S$ " shape for the entire $\mathrm{f1} / \mathrm{I}$ relationship. The $\mathrm{f} 2 / \mathrm{I}$ and $\mathrm{f} / \mathrm{I}$ relationships were similar but the initial shallow region was longer, and fewer cells exhibited a flattening of the steeper slope at higher currents. Using least-squares linear regression, we selectively fitted the first 2 regions, designated "primary" and "secondary" (Kernell, 1965), of the f/I relationships with 2 straight lines of different slope. The grouped data for the slopes, and transition frequencies between them, for the first 3 spike intervals are given in Table 4 . In summary, both primary and secondary slopes be-

Table 2. Action potential characteristics

\begin{tabular}{lccc} 
& $\begin{array}{l}\text { L2/3 } \\
(n=22)\end{array}$ & $\begin{array}{l}\text { Slender L5 } \\
(n=10)\end{array}$ & $\begin{array}{l}\text { Thick L5 } \\
(n=6)\end{array}$ \\
\hline Threshold above resting potential $^{b}(\mathrm{mV})$ & $23 \pm 6^{*}$ & $18 \pm 4$ & $14 \pm 3$ \\
Absolute threshold $(\mathrm{mV})$ & $-52 \pm 6$ & $-53 \pm 4$ & $-55 \pm 3$ \\
Peak height above threshold $(\mathrm{mV})$ & $86 \pm 8$ & $83 \pm 6^{* *}$ & $91 \pm 6^{* *}$ \\
Width at half height above threshold (msec) & $0.57 \pm 0.09$ & $0.61 \pm 0.09$ & $0.49 \pm 0.03^{*}$ \\
Rate of rise (V/sec) & $553 \pm 125$ & $466 \pm 44^{*}$ & $528 \pm 36$ \\
Rate of fall (V/sec) & $111 \pm 19$ & $104 \pm 25$ & $161 \pm 9^{*}$ \\
Ratio of rate of rise to rate of fall & $5.0 \pm 0.8$ & $4.7 \pm 1.1$ & $3.3 \pm 0.3^{*}$
\end{tabular}

a Only thick L 5 cells in which single spikes could be evoked by just suprathreshold current pulses were included in this analysis.

- Threshold was defined as the point at which the rate of change of voltage exceeded $50 \mathrm{~V} / \mathrm{sec}$. This point agrees well with subjective determinations of threshold (Andersen et al., 1987). Although a computer program was used to detect threshold automatically, the result was always checked by visual inspection to ensure that fast-rising noise had not been mistaken for threshold.

' Rates of rise and fall were computed over the voltage range between 30 and $70 \%$ of peak spike amplitude. Over this range the voltage trajectories were almost linear, and this measure should be less susceptible to noise than peak rate. 
came shallower with each successive interspike interval but the transition frequency between the 2 remained approximately the same. Thus, the primary slopes became progressively longer. For all 3 intervals L2/3 cells had steeper secondary slopes than slender L5 cells, but the primary slopes were not significantly different between the 2 cell classes. For all 3 classes of cell, steady-state firing frequency was a single, linear function of injected current (Fig. 9). The slope of this relationship was shallower for thick L5 cells than for L2/3 and slender L5 cells (Table 5). There was no evidence of a steeper, secondary slope for any cell. With all cells considered together, the slope of the fss/I relationship was positively correlated with $R_{\text {in }}$ (tau $=0.45, p<$ 0.001).

Spike frequency adaptation. We also used data of the kind shown in Figure 7 to investigate the change in spike frequency over time in response to constant current. Instantaneous spike frequency was plotted against interval number for $400-\mathrm{msec}$ current pulses of different strength. Both L2/3 and slender L5 neurons showed a much sharper drop in spike frequency over the first few intervals than during later intervals (Fig. 10, $A, B$ ). In thick L5 cells, an initial burst of high-frequency spiking for the first few intervals (the number depending on the burst pattern of the particular cell) was followed by single spikes whose frequency, after an initial "dip," remained almost constant until the end of the pulse (Fig. 10C). This "dip" in spike frequency is presumably caused by the pronounced membrane hyperpolarization that follows a burst.

In order to determine whether the degree of spike frequency adaptation was significantly different between the cell classes, we required a measure of adaptation for each cell. Because adaptation in these neurons varied with firing frequency (as shown by the fact that the $f / I$ relationship was sigmoidal or bilinear for the first few spike intervals, but linear for fss), we measured adaptation at a single fss for each cell. The particular fss that we chose was 26.5 spikes/sec, which was midway between the means of all the highest and lowest fss frequencies recorded. We included only cells for which we had a data sweep with an fss within $\pm 10 \%$ of this value. To give a measure of the overall amount of spike frequency adaptation from the first interspike interval to steady firing at the end of the pulse, we expressed fss as a percentage of $\mathrm{fl}$ (Fig. 10D). The firing frequency at the

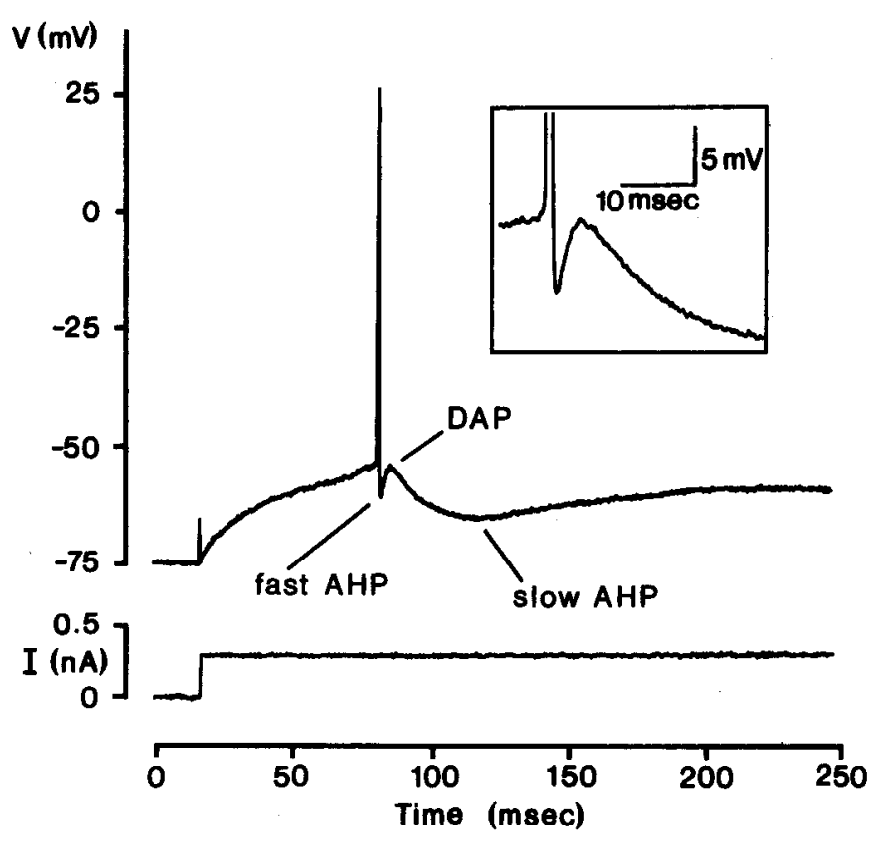

Figure 3. Action potential and spike afterpotentials evoked in an L2/3 cell by a prolonged, just suprathreshold, injected current pulse (lower trace). Inset shows an average of 4 sweeps, at higher gain and expanded time base, from the same cell.

end of the $400-\mathrm{msec}$ pulse was a greater percentage of the initial firing frequency for slender L5 cells than for the other 2 classes; i.e., there was less spike frequency adaptation. Although the degree of adaptation for thick L5 cells was not significantly different from L2/3 cells, it must be remembered that thick L5 cells have a very different pattern of repetitive firing because of their bursting behavior.

\section{Discussion}

The aim of this study was to determine whether pyramidal neurons of different morphology in layers $2 / 3$ and 5 of rat visual cortex (Larkman and Mason, 1990) have distinctive electrophysiological properties. On morphological grounds we have recognized 3 cell classes and have shown that they differ in

Table 3. Spike afterpotentials: AHP and DAP

$\mathbf{L} 2 / 3$

Slender L5

Thick L5 ${ }^{a}$

\begin{tabular}{lccr}
\hline Fast AHP & & & \\
Peak voltage $b(\mathrm{mV})$ & $-9.4 \pm 2.1(14)^{* *}$ & $-10.1 \pm 4.6(8)$ & $-5.4 \pm 3.3(6)^{* *}$ \\
Time-to-peak $(\mathrm{msec})$ & $0.7 \pm 0.2(14)$ & $1.6 \pm 0.3(8)^{*}$ & $0.7 \pm 0.2(6)$ \\
DAP & & & \\
Peak voltage $^{b}(\mathrm{mV})$ & $-6.3 \pm 2.5(14)$ & $-8.7 \pm 4.5(8)$ & $-2.7 \pm 3.0(6)^{*}$ \\
Time-to-peak $(\mathrm{msec})$ & $3.5 \pm 0.7(14)$ & $7.2 \pm 2.0(7)^{*}$ & $4.1 \pm 2.0(6)$ \\
Slow AHP & & & \\
Peak voltage $^{b}(\mathrm{mV})$ & $-12.8 \pm 1.6(14)$ & $-17.0 \pm 3.1(8)^{*}$ & $-13.6 \pm 2.6(6)$ \\
Time-to-peak $^{c}(\mathrm{msec})$ & $31.5 \pm 5.8(14)$ & $54.5 \pm 14.4(8)^{*}$ & $30.2 \pm 7.9(6)$ \\
Duration $^{d}(\mathrm{msec})$ & $171 \pm 40(10)$ & $211 \pm 38(7)$ & $141 \pm 16(2)$
\end{tabular}

a Only cells in which single spikes could be evoked by just suprathreshold current pulses were used for measurements of afterpotentials.

b All peak voltages measured with respect to spike threshold.

c All times-to-peak measured from the point at which the spike downstroke crossed spike threshold.

¿Measured from spike repolarization to attainment of steady "plateau" voltage. (Note that, because 400 -msec current pulses were used to elicit the spikes, the current pulse was present throughout the duration of the afterpotentials.) 
A1

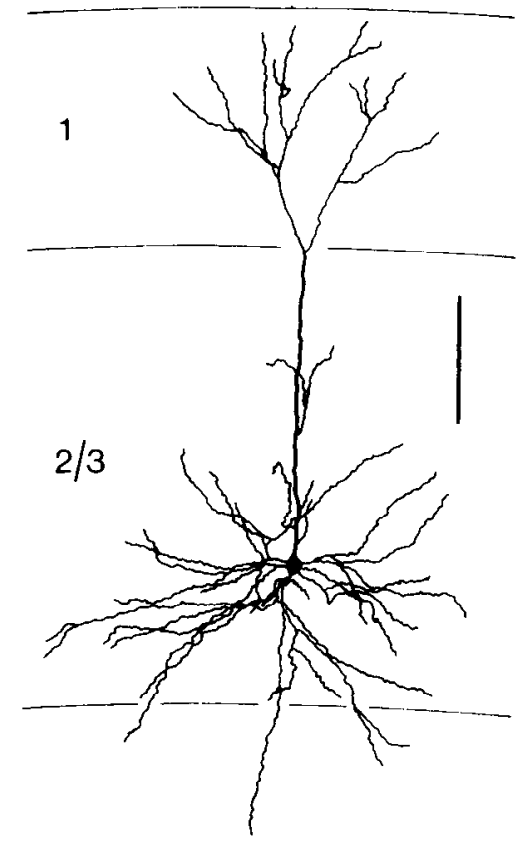

4

\section{A 2}

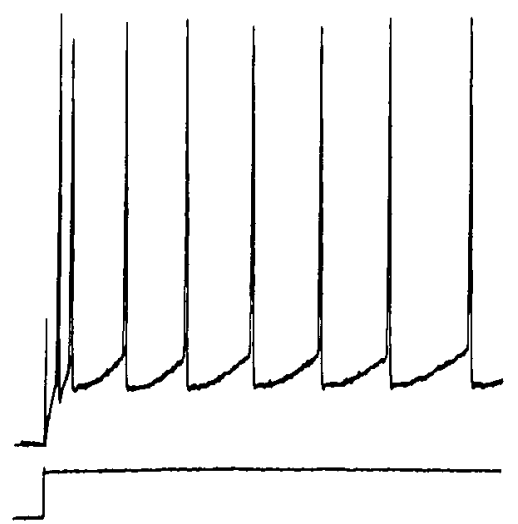

B1

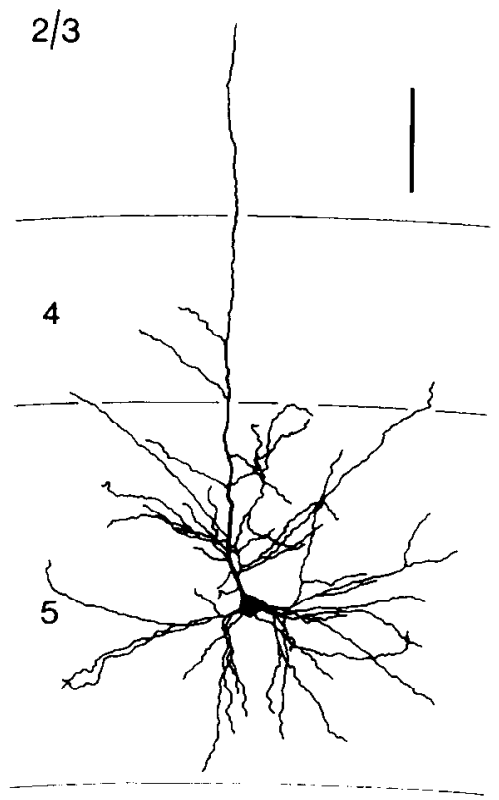

B 2

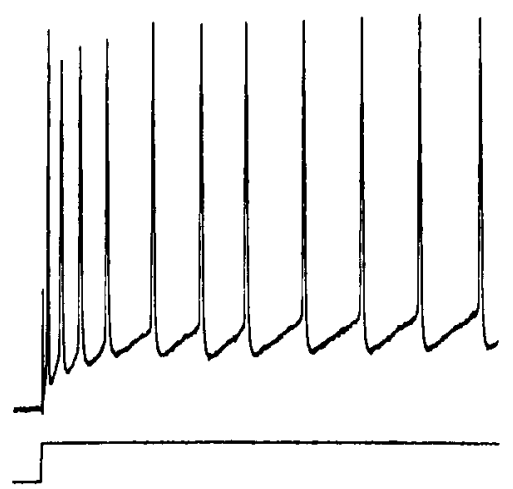

Thick L5

C1

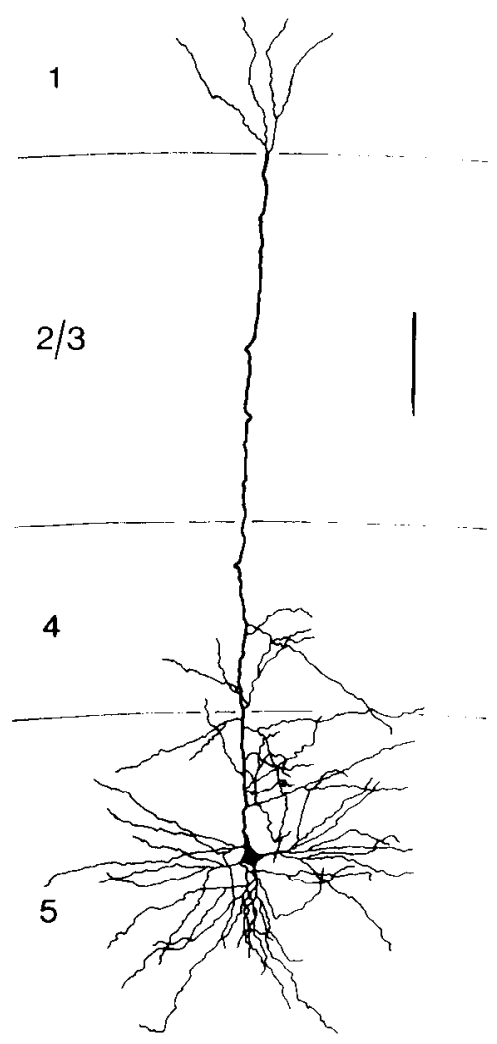

C 2

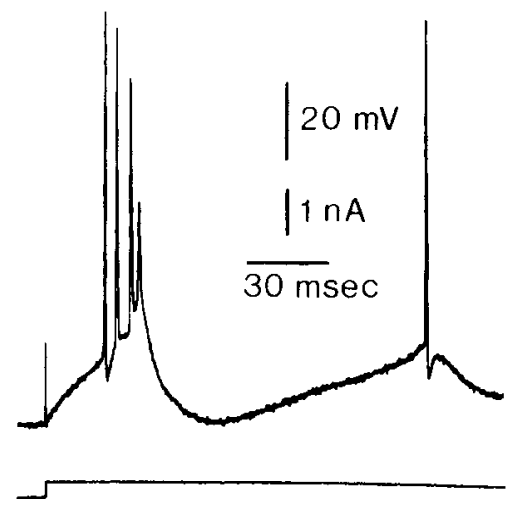

Figure 4. Morphology and repetitive firing behavior of the 3 classes of neuron. Top panels are camera lucida drawings of an L2/3 cell (Al), a slender L5 cell $(B 1)$, and a thick L5 cell $(C 1)$. Scale bars, $100 \mu \mathrm{m}$. Lower panels $(A 2, B 2, C 2)$ show repetitive firing in the same neurons produced by injected current pulses. Current strengths have been chosen so that the first interspike interval is approximately the same for all 3 neurons. Upper trace, Voltage; lower trace, current. Calibrations apply to all 3 panels.

subthreshold and suprathreshold electrophysiological properties. However, our sample is small and the finding of a single example of an L5 cell with twin apical dendrites (Larkman and Mason, 1990), together with evidence for atypically oriented pyramids throughout layers 2 to 6 (Miller, 1988), demonstrates that other kinds of pyramidal neurons are also present in layers $2 / 3$ and 5 . Subdivision of the classes we have established might be possible with a larger sample of cells. This is particularly likely for the slender L5 cells, which, for most morphological and electrophysiological measures, showed the greatest individ- ual cell variation. Although we found significant differences between class medians for a number of electrophysiological measures, the overlap in values between individual cells of different classes meant that, with the exccption of bursting, no single electrophysiological measurement unequivocally predicted cell morphology.

Our values for basic cell properties such as resting potential, apparent input resistance, membrane time constant, action potential size, and shape are in agreement with previous studies of neocortical neurons in vitro (c.g., Connors et al., 1982; Staf- 
A1

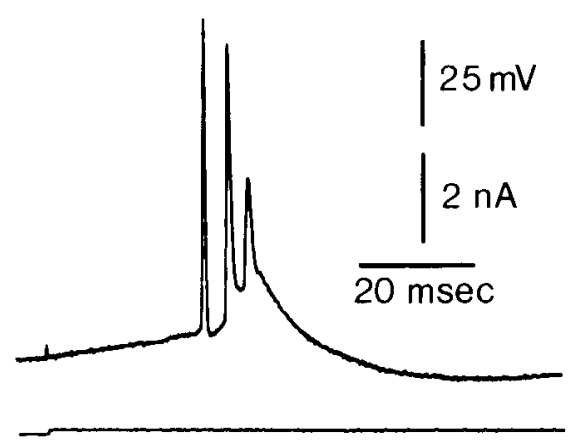

B1

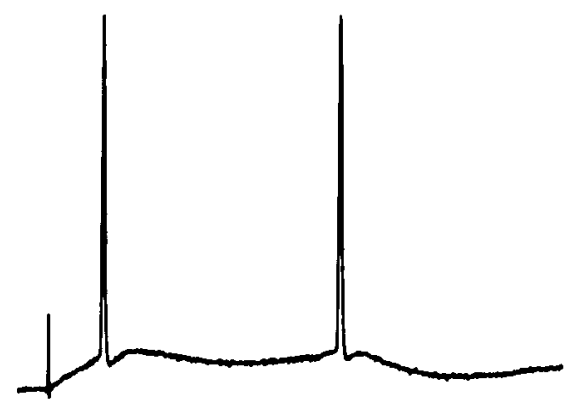

$-$
A2

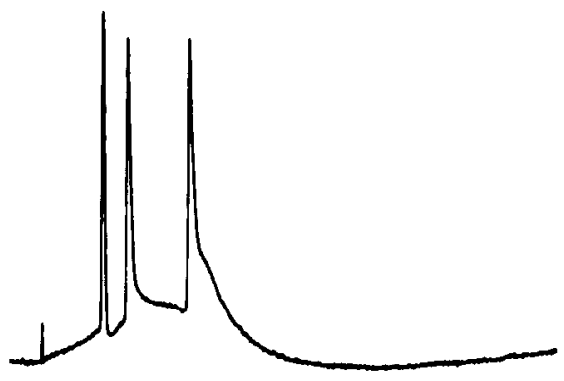

B2

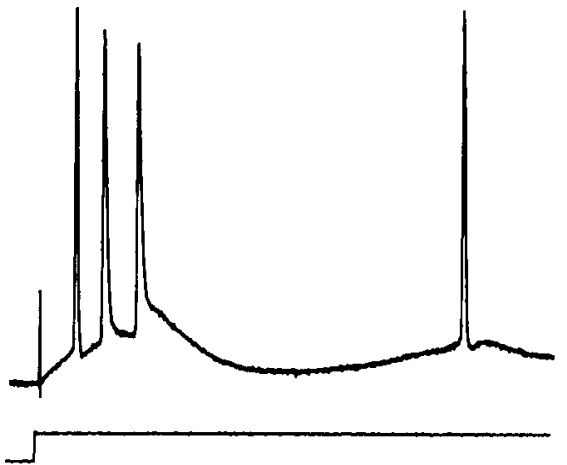

A3

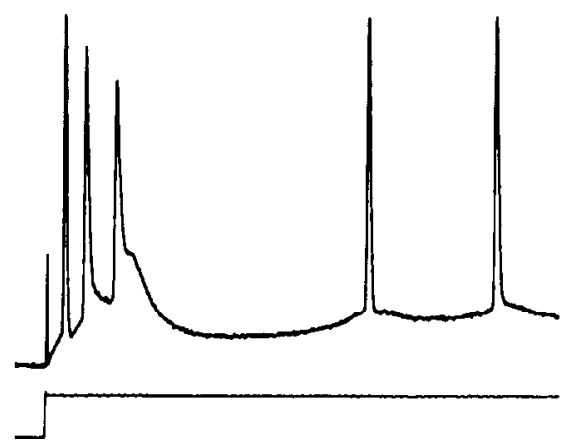

B3

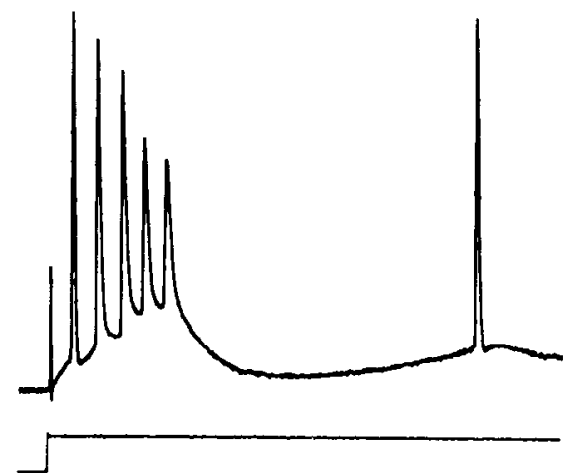

Iigure 5. Changing burst patterns in response to varying current strength. Results from 2 different thick L5 cells are illustrated. Cell A fired a burst in response to the smallest currents that evoked spike activity $(A I)$. Increasing the current $(A 2, A 3)$ caused the burst pattern to change slightly. Cell $\mathrm{B}$ fired single spikes in response to just suprathreshold currents $(B I)$. Bursting behavior developed as the current was increased $(B 2$, $B 3$ ). Calibrations apply to all panels.

strom el al., 1984b; McCormick et al., 1985; Thomsun, 1986; Scharfman and Sarvey, 1987; Sutor and Zieglgänsberger, 1987; Bindman et al., 1988). We are confident, therefore, that the quality of our intracellular impalements was not seriously compromised by the use of relatively coarse-tipped, HRP-filled micropipettes.

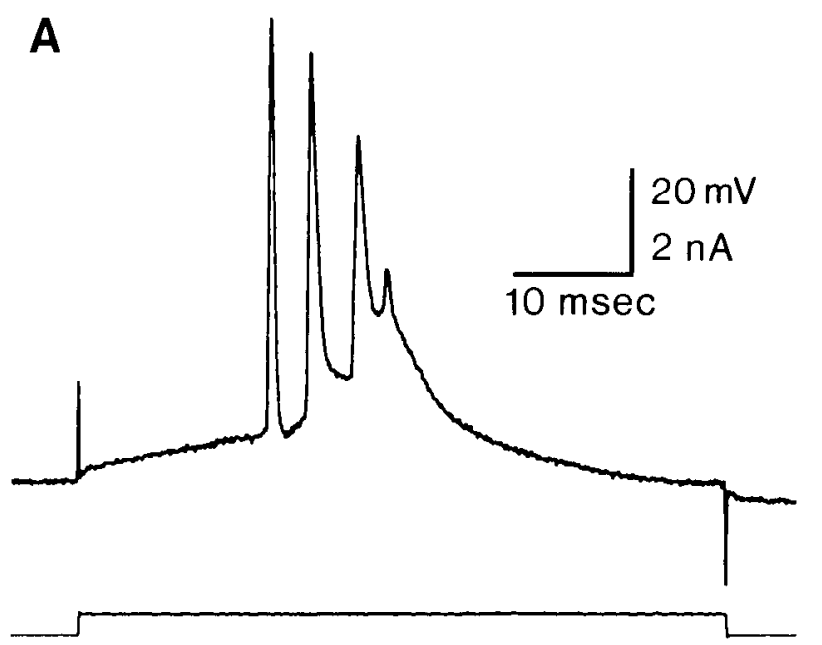

\section{Subthreshold properties}

Membrane time constant. The membrane time constant, measured from the voltage decay following a brief current pulse. was considerably longer for slender L5 neurons than for the other 2 cell classes. These values will equal the true membrane

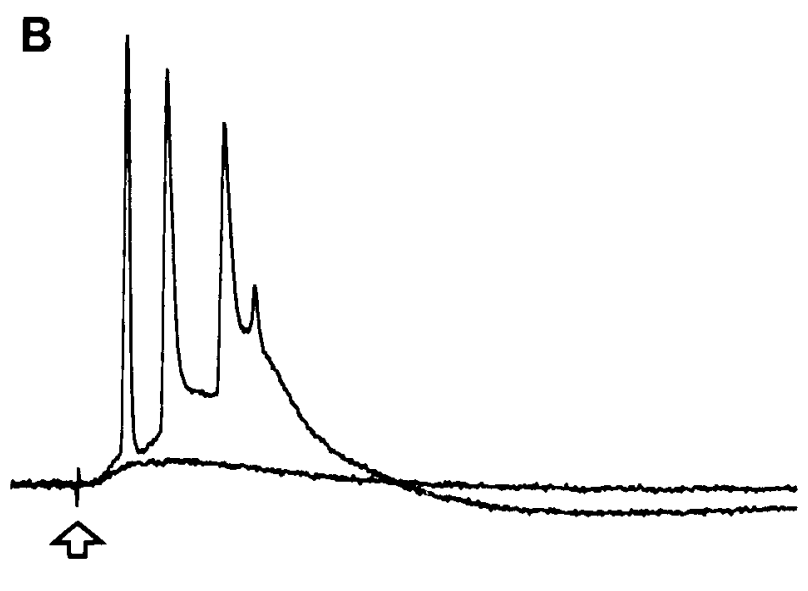

Figure 6. Burst firing in response to orthodromic stimulation. A. Burst (upper trace) evoked in a thick L5 cell by an injected current pulse (lower trace). $B$. Response of the same cell to extracellular stimulation of L5. Stimulus artifact is arrowed. Two sweeps are superimposed. The first stimulus gave rise to a depolarizing synaptic potential but was subthreshold for spiking. Slightly increasing the stimulus voltage caused the cell to fire a burst that was almost identical to the burst produced by intracellular current injection. Time and voltage calibrations apply to both panels. 
A1

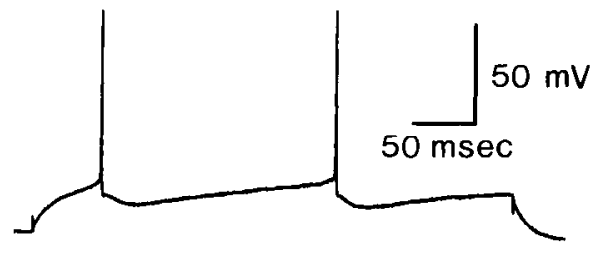

B1

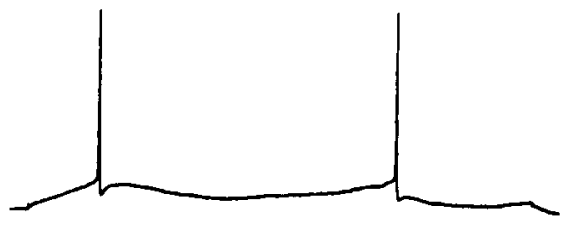

C1

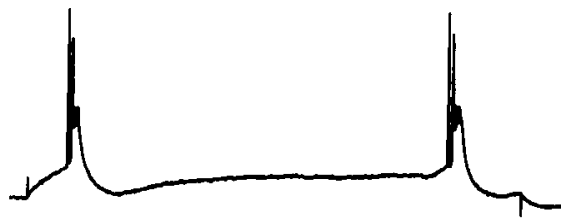

A 2

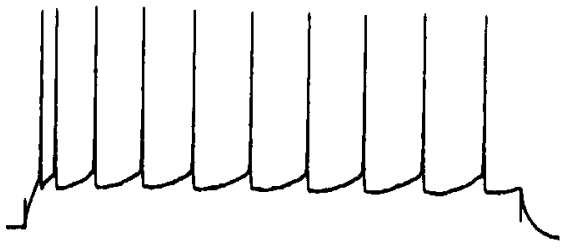

B 2

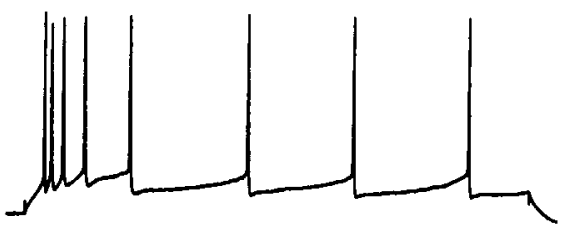

C 2

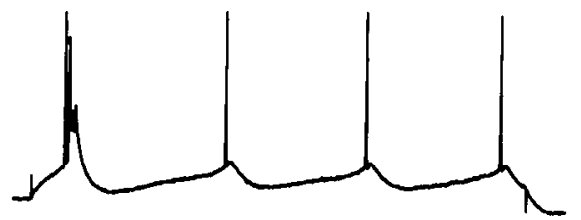

A3

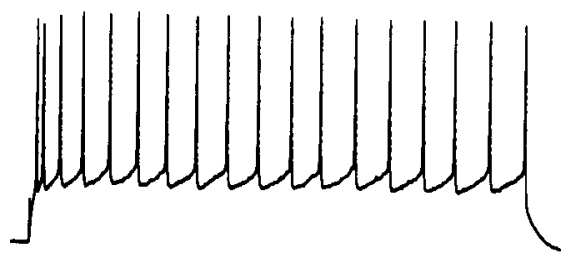

B 3

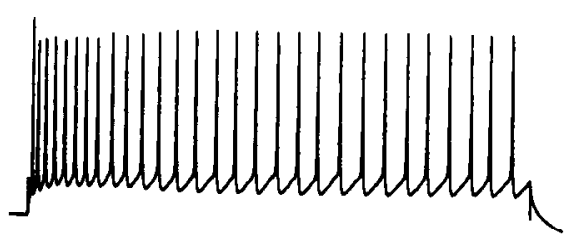

C3

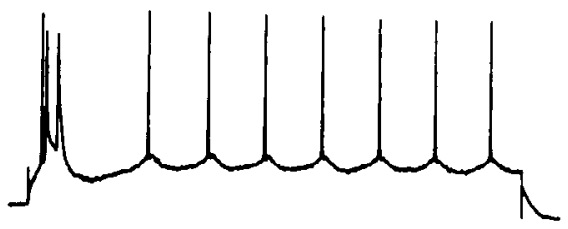

Figure 7. Repetitive firing. Firing patterns in response to approximately $400 \mathrm{msec}$ duration, injected current pulses (current traces not shown) for an L2/3 cell $(A I-A 3)$, a slender L5 cell $(B I-B 3)$, and a thick L5 cell $(C I-C 3)$. Current strength increases from left to right. Calibrations apply to all pancls.

time constants only if a number of conditions are satisfied (Rall, 1969). These include the requirement that the decay must be passive, i.e., not influenced by active conductances. Although the entire later part of the voltage decay for L2/3 cells appeared to conform to a single exponential, consistent with passive decay, this clearly was not the case for L5 cells. Particularly for thick L5 cells, the later part of the voltage decay gradually became more rapid than expected and the membrane potential overshot the resting level. A similar phenomenon has been reported for spinal motoneurons in vivo (e.g., Ito and Oshima, 1965; Gustafsson and Pinter, 1984; Fleshman et al., 1988). Although we measured membrane time constant from a region of the voltage decay before the apparent onset of this phenomenon, it may still have caused us to underestimate membrane time constant (Fleshman et al., 1988; Rose and Dagum, 1988; Rose and Vanner, 1988). Thus, the short membrane time constant of thick L5 cells could be artifactual, but the difference in time constant between slender L5 cells and L2/3 cells might be even greater than reported here.

Current/voltage relations. All cells tested showed a decrease in $R_{\text {in }}$ with increasing size of hyperpolarizing current pulses, and all but 2 cells showed an increase in $R_{\text {in }}$ with depolarization. Such inward (or anomalous) rectification has been described previously for neocortical neurons (Connors et al., 1982; Stafstrom et al., 1982; Stafstrom et al., 1984b; Sutor and Zieglgänsberger, 1987; Bindman et al., 1988; Avoli and Olivier, 1989).

\begin{tabular}{|c|c|c|}
\hline & $\mathrm{L} 2 / 3$ & Slender L5 \\
\hline \multicolumn{3}{|l|}{ 1st interspike interval } \\
\hline Primary slope (spikes/sec/nA) & $169 \pm 72$ & $137 \pm 55$ \\
\hline Secondary slope (spikes/sec/nA) & $1059 \pm 439(14)^{* *}$ & $458 \pm 147(10)^{* *}$ \\
\hline Transition freq. (spikes/sec) & $27 \pm 11$ & $25 \pm 13$ \\
\hline \multicolumn{3}{|l|}{ 2nd interspike interval } \\
\hline Primary slope (spikes/sec/nA) & $107 \pm 32$ & $91 \pm 29$ \\
\hline Secondary slope (spikes/sec/nA) & $603 \pm 324(14)^{* *}$ & $300 \pm 114(10)^{* *}$ \\
\hline Transition freq. (spikes/sec) & $27 \pm 8 \quad(13)$ & $24 \pm 9$ \\
\hline \multicolumn{3}{|l|}{3 rd interspike interval } \\
\hline Primary slope (spikes/sec/nA) & $84 \pm 29$ & $63 \pm 16$ \\
\hline Secondary slope (spikes/sec/nA) & $429 \pm 168(10)^{* *}$ & $221 \pm 95(10)^{* *}$ \\
\hline Transition freq. (spikes/sec) & $32 \pm 7 \quad(10)$ & $25 \pm 16$ \\
\hline
\end{tabular}




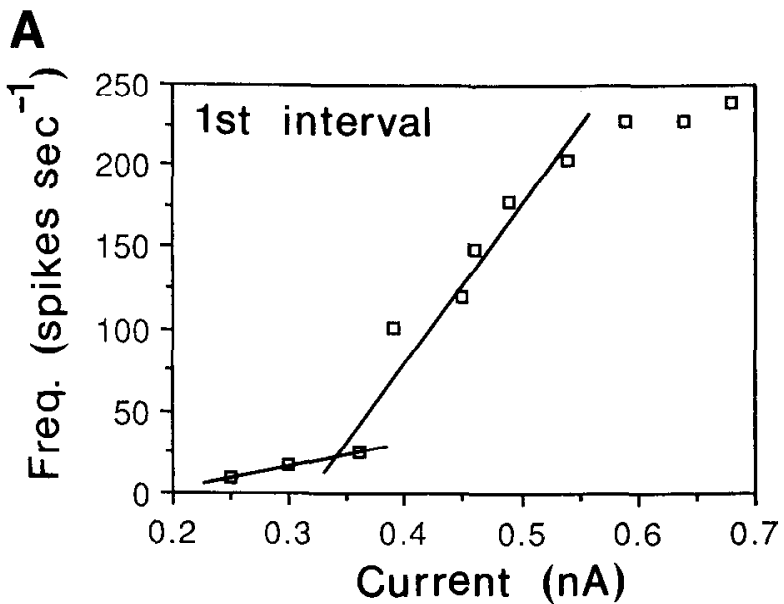

B

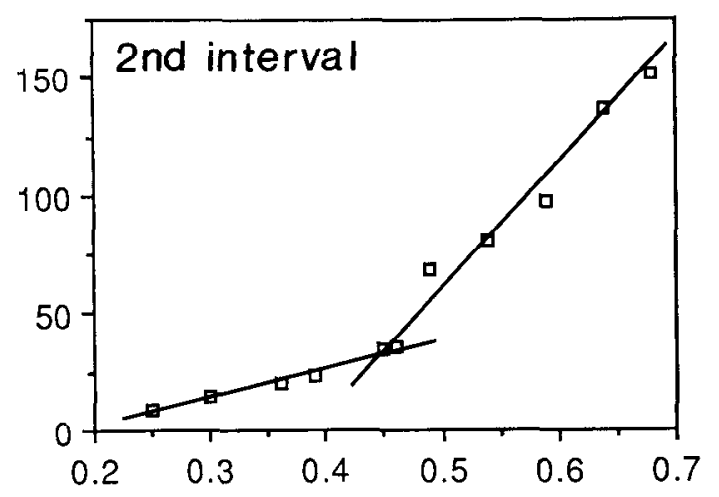

C

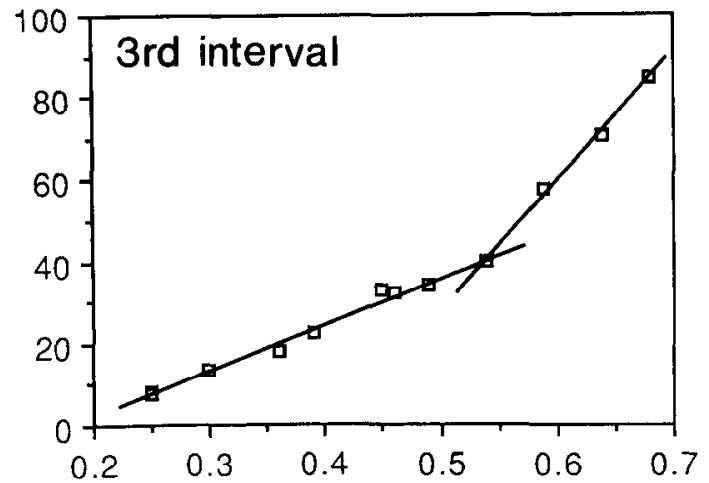

Figure 8. Frequency/current relationship for the first 3 interspike intervals for an L2/3 cell. Lines fitted to the points represent the primary and secondary slopes of the $f / I$ relationships (see text). Axis labels apply to all 3 graphs.

The rectification positive to resting potential is probably due to the activation of a persistent sodium current (Connors et al., 1982; Stafstrom et al., 1982; Stafstrom et al., 1984b; Stafstrom et al., 1985; Sutor and Zieglgänsberger, 1987). For L2/3 cells, the hyperpolarizing inward rectification in the absence of sag/ overshoot suggests the presence of a fast inward rectifier similar to that found in layers 2 and 3 of frontal cortex (Sutor and Zieglgänsberger, 1987), in olfactory cortex (Constanti and Galvan, 1983a), and in other brain areas (Osmanovic and Shefner, 1987; Griffith, 1988).

Phenomena similar to the sag and overshoot/undershoot ob-

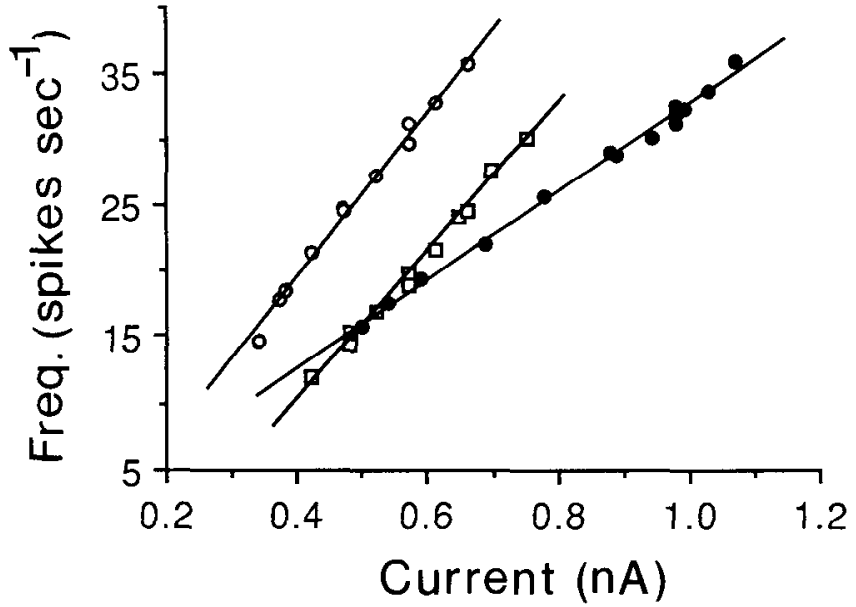

Figure 9. Frequency/current relationship for steady-state firing for an L2/3 cell (squares), a slender L5 cell (open circles), and a thick L5 cell (closed circles). Lines were fitted by least-squares lincar regression.

served in L5 cells in the present study have been found in a wide variety of vertebrate and invertebrate neurons (e.g., Halliwell and Adams, 1982; Mayer and Westbrook, 1983; Arbas and Calabrese, 1987; Hounsgaard and Midtgaard, 1988; Lasater, 1988), including those of mammalian neocortex (Stafstrom et al., 1984b; Penit-Soria et al., 1987; Spain et al., 1987; Avoli and Olivier, 1989). They suggest the presence of a slow inward rectifier in the L5 cells, although ionic currents such as the M current (Adams et al., 1982; Constanti and Galvan, 1983b; Halliwell, 1986; McCormick and Prince, 1986; Brown, 1988), a calcium-sensitive potassium current (Crepel and Penit-Soria, 1986), or a low-threshold calcium current (Llinás and Jahnsen, 1982; Deschênes et al., 1984; Crepel and Penit-Soria, 1986; Friedman and Gutnick, 1987) may be involved. However, the correlation between the amounts of sag, overshoot, and undershoot found among L5 cells in the present study is consistent with a single ionic mechanism underlying them all. We have not excluded the possibility that $L 5$ neurons possess both a slow and a fast inward rectifier, as has been found for neurons in inferior olive (Yarom and Llinás, 1987) and dorsal raphe (Williams et al., 1988).

It seems likely that sag and overshoot are related to the late deviation from exponential decay of the voltage trajectory following a brief, hyperpolarizing current pulse (see above). The correlation between the magnitudes of all these effects, across the 3 cell classes, is consistent with this conclusion, which is also supported by studies on spinal motoneurons (Gustafsson and Pinter, 1984; Fleshman et al., 1988). Assuming both cell classes have similar kinetics for the underlying ionic mechanisms, the smaller amount of sag and overshoot/undershoot in

Table 5. Frequency/current relations (steady-state)

\begin{tabular}{ll} 
Cell class & $\begin{array}{l}\text { Steady-state slope } \\
\text { (spikes/sec/nA) }\end{array}$ \\
\hline L2/3 & $56 \pm 14(16)$ \\
Slcnder L5 & $66 \pm 22(10)$ \\
Thick L5 & $41 \pm 10(14)^{*}$ \\
\hline
\end{tabular}



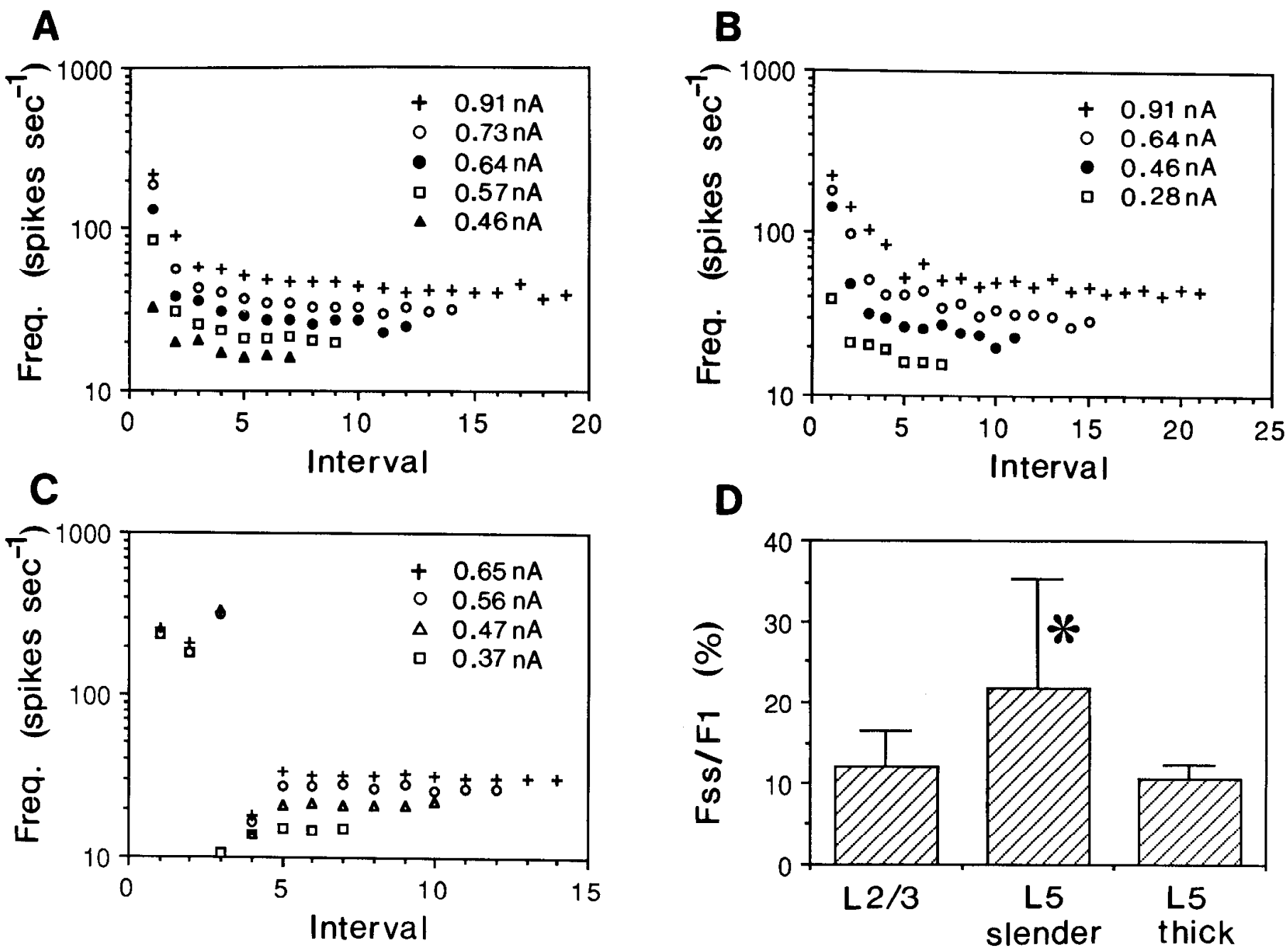

Figure 10. Spike frequency adaptation. Instantaneous spike frequency as a function of spike interval for an L2/3 cell (A), a slender L5 cell (B), and a thick L5 cell $(C)$. A selection of current strengths is shown for each cell. In $C$, note stereotyped burst pattern (with the exception of the lowest current strength) and the "dip" in frequency following the burst. $D$, Mean spike frequency adaptation (steady-state firing frequency as a percentage of first interval firing frequency; see text) for all 3 neuron types. Bars indicate SDs. Asterisk indicates that the mean spike frequency adaptation of slender L 5 cells was significantly different $(p<0.01)$ from that of thick L 5 cells and L $2 / 3$ cells.

slender L5 cells than in thick L5 cells could be due to the longer membrane time constants of slender L5 cells (Schwindt et al., 1988a). However, this explanation does not account for the lack of sag and overshoot/undershoot in L2/3 cells, because the time constants of $L 2 / 3$ cells are only slightly longer than those of thick L5 cells and much shorter than those of slender L 5 cells.

The presence of voltage-sensitive currents active at, or very close to, resting potential is likely to result in an $\mathrm{I} / \mathrm{V}$ plot that has no, or only a very short, linear region. We measured $R_{\text {in }}$ over the voltage range just negative to rest. The mean value was lowest for thick L5 neurons, highest for slender L5 neurons, and intermediate for $\mathrm{L} 2 / 3$ neurons. The presence of sag will probably have caused us to underestimate the input resistance of L5 neurons (Zengel et al., 1985; Fleshman et al., 1988; Rose and Dagum, 1988). Thus, at least some of the difference in $R_{\text {in }}$ between thick L5 and L2/3 neurons is likely to be artifactual, but the difference in $R_{\mathrm{in}}$ between slender $\mathrm{L} 5$ and $\mathrm{L} 2 / 3$ neurons could be even greater than that reported here.

What could be the functional roles of nonlinearities in the current/voltage relation? A sag mechanism will exert a "poten- tial clamping" effect on membrane potential (Adams et al., 1982). The anomalous rectifier responsible for sag and overshoot in L5 neurons of cat sensorimotor cortex has been implicated in spike frequency adaptation and control of cell excitability after repetitive firing via an effect on the time course and amplitude of the afterhyperpolarizations (Spain et al., 1987; Schwindt et al., 1988a). It has been suggested that persistent inward currents, such as those responsible for inward rectification positive to rest, could act to cancel out leakage conductances and hence selectively alter neuronal cable properties (Llinás and Sugimori, 1984; Adams and Galvan, 1986; Yoshii et al., 1988).

\section{Suprathreshold properties}

Action potential. Neurons of all 3 classes had similar action potentials (but see below for bursting behavior of thick L5 cells). Although there were small differences in amplitude and rate of rise between cell classes, the most obvious difference was the greater rate of spike repolarization in thick L 5 cells, which was also responsible for the decreased width and smaller rise-rate to fall-rate ratio of the spikes in these cells. However, all 3 cell 
classes had rise-rate to fall-rate ratios in agreement with those determined for pyramidal cells in sensorimotor cortex (McCormick et al., 1985). Differences in spike shape between cell classes presumably reflect differences in the type, distribution, or amount of the sodium and potassium conductances that underlie action potentials in neocortical neurons (Connors et al., 1982; Stafstrom et al., 1984b; Huguenard et al., 1988; Schwindt et al., 1988c; Zona et al., 1988).

Spike afterpotentials. Single spikes in all cells were followed by a similar sequence of spike afterpotentials. An carly afterhyperpolarization (fast AHP), which appeared as a continuation of the spike downstroke, was followed by a depolarization (DAP) and then a more prolonged AHP (slow AHP). A similar pattern of spike afterpotentials can be seen in previous reports of studies on neocortical cells (McCormick and Prince, 1987; Bindman et al., 1988; Schwindt et al., 1988c). It was notable that slender L5 cells had times-to-peak, for all 3 afterpotentials, that were longer than those of the other cell classes. Perhaps this is due to the longer membrane time constant of these cells. The DAP in thick L5 cells drove the membrane potential to a more positive level than in the other 2 cell classes. The DAP may be due to calcium currents (Friedman and Gutnick, 1987; Schwindt et al., 1988c), and it is possible that its greater prominence in thick $\mathrm{L} 5$ cells is related to the bursting behavior of these neurons (see below). However, in the present study, we could not assess the extent to which passive repolarization of the membrane, during a period between the fast and slow AHPs, might have contributed to the DAP.

Burst firing. Of the 3 pyramidal cell classes described in this study, only the thick L5 cells showed bursting behavior. Although there was considerable variation between cells, the burst pattern in response to injected current was characterized by a number of decrementing and broadening spikes riding on a depolarizing envelope and followed by a pronounced hyperpolarization. In response to current pulses substantially stronger than threshold, thick L5 cells fired a single burst followed by a train of single spikes. Neurons with similar behavior have been described previously in neocortex (McCormick et al., 1985; Jones and Heinemann, 1988; Montoro et al., 1988). In agreement with these studies, we found that the threshold for bursting was sometimes greater than for single spikes, and that bursting could develop gradually as the current was increased. Because bursts could be evoked by intracellular current injection, and because burst firing was influenced by the strength of the injected current, it is likely that bursts were generated by intrinsic membrane currents rather than by synaptic interactions. Although bursts could also be evoked by orthodromic stimulation, this may have been due to the suprathreshold EPSPs triggering the intrinsic currents responsible for burst firing. The failure of orthodromic stimulation to evoke a burst in 1 of the 6 thick L5 cells tested might be explained by a different balance between synaptic excitation and inhibition in that case.

Calcium currents are believed to underlie intrinsic burst firing in hippocampal CA3 neurons (Wong and Prince, 1978, 1981; Johnston et al., 1980), and it is possible that similar mechanisms are responsible for bursting in thick L5 cells of rat visual cortex. Both high-threshold and low-threshold calcium currents have been found in neocortical neurons (Connors et al., 1982; Stafstrom et al., 1985; Franz et al., 1986; Friedman and Gutnick, 1987). However, there is evidence for a sodium component of the depolarizing envelope in both hippocampal and neocortical neurons (Konnerth et al., 1986; Deisz and Prince, 1987; Deisz,
1988; Schwindt et al., 1988c). Furthermore, since it is possible to cause normally nonbursting neocortical neurons to burst by blocking potassium currents (Connors and Gutnick, 1984; Schwindt et al., 1988c; Friedman and Gutnick, 1989), outward currents are almost certainly involved in the control of bursting. From the diversity of burst firing behaviors found in guinea pig visual cortex, Montoro et al. (1988) concluded that bursting mechanisms were likely to vary between different neurons.

Of the 3 classes of cell reported here, only the thick L5 neurons appear to possess the appropriate balance of inward and outward currents to generate intrinsic bursts. However, we have not excluded the existence of other types of bursting neuron in neocortex. Indeed, previous studies have reported burst firing neurons in other cortical layers, including L3 in some cases (Connors et al., 1982; Artola and Singer, 1987; Friedman and Gutnick, 1987; Montoro et al., 1988; Thomson et al., 1988). In some cases this disparity may be due to the use of different spccics or cortical areas, but comparison between some of these results and our own is complicated by difficulties in defining exactly what constitutes burst firing, the possibility that different cell types were sampled, and the lack of morphological data for comparison. In a pioneering electrophysiological and morphological study of sensorimotor and cingulate cortex in vitro, McCormick et al. (1985) found that bursting cells were confined to layers 4 and 5 , whereas regular-spiking cells were distributed throughout layers 2 to 6 . Although both cell types were pyramidal, bursting cells could not be distinguished from regular-spiking cells on morphological grounds, perhaps because a detailed structural analysis was not performed.

What are the functional implications of bursting? Bursting could serve to amplify a neural signal and synchronize activity in a population of postsynaptic cells (Hablitz, 1986). The highfrequency spiking that occurs during a burst could be of importance in the initiation of long-term potentiation (Hablitz, 1986; Gamble and Koch, 1987) and might be involved in epileptogenesis (Gutnick and Friedman, 1986; Prince and Connors, 1986). The fact that bursting neurons fire an initial burst followed by trains of single spikes means that they will respond strongly but transiently to a brief, new stimulus, yet produce a sustained response to a maintained input. Burst firing in other neocortical neurons is voltage sensitive, bursts being inactivated by maintained depolarization (McCormick et al., 1985; Jones and Heinemann, 1988; Montoro et al., 1988). This raises the further possibility that thick L5 neurons could operate in 2 modes, perhaps with switching between burst-firing and tonicfiring modes being controlled by modulatory neurotransmitters (McCormick and Prince, 1988; Steriade and Llinâs, 1988). The potential flexibility in input-output relations conferred by these mechanisms might have important consequences for integration in the neocortex.

Repetitive firing. We found that $\mathrm{f} / \mathrm{I}$ relationships for the first few spike intervals in L2/3 and slender L5 cells were " $S$ " shaped or bilinear, with an initial shallow slope. Similar results have been reported previously for several neuron types (e.g., Kernell, 1965; Koike et al., 1970; Gustafsson et al., 1978; Gustafsson and Wigström, 1981; Lanthorn et al., 1984; Jodkowski et al., 1988). However, a shallow, initial region of the $\mathrm{f} / \mathrm{I}$ relationship has not been well documented in neocortical neurons in vitro, although a hint of such a region is evident in records from rat sensorimotor cortex (McCormick and Prince, 1987). This could reflect a difference between species or cortical areas, but a shallow primary slope may have been missed in previous studies 
because it exists over only a short current range, or because its existence may depend on membrane potential (Storm, 1988). The slopes of the early interval frequency-current relationships found in this study are steeper than those previously reported for hippocampal and neocortical neurons (Ogawa et al., 1981; Lanthorn et al., 1984; McCormick et al., 1985; McCormick and Prince, 1987; Connors et al., 1988; Avoli and Olivier, 1989). The difference is particularly marked for the $L 2 / 3$ cells, where the very steep secondary slopes reflect the tendency for spike "pairing" and abrupt recruitment of spikes into the initial phase of high-frequency spiking, as the current was increased. For both I .2/3 and slender L5 cells, the primary slope became longer with each successive interspike interval. However, it also became shallower and the transition between primary and secondary range firing occurred at approximately the same frequency for the first 3 intervals. This is similar to the behavior of cat spinal motoneurons (Kernell, 1965), but different from spinocerebellar tract neurons (Gustafsson et al., 1978) and hippocampal CA1 cells (Gustafsson and Wigström, 1981), in which the transition frequency increases for successive intervals.

For all cells we found that a plot of steady-state firing frequency against injected current had only a single, linear range. This has also been reported for hippocampal CAl cells and rat somatosensory cortex (Lanthorn et al., 1984; Connors et al., 1988), although the slopes were somewhat shallower than for all 3 classes of pyramidal ncurons studied here. However, it is possible that a steeper (Kernell, 1965; Koike et al., 1970), or shallower (Stafstrom et al., 1984a; Avoli and Olivier, 1989) secondary slope would have been revealed if we had been able to inject larger currents. We found a positive correlation between $R_{\text {in }}$ and the slope of the steady-state firing frequency versus current relationship. Such a correlation was not found for hippocampal CA1 cells (Lanthorn et al., 1984) or for spinal motoneurons (Schwindt, 1973).

The pronounced decrease in firing frequency over time in response to a constant current pulse (spike frequency adaptation) appears to be a ubiquitous property of pyramidal cells (e.g., Koike et al., 1970; Lanthorn et al., 1984; Stafstrom et al., 1984a; McCormick et al., 1985; Connors and Kriegstein, 1986; Connors et al., 1988). Usually, most of the adaptation occurs during the first few interspike intervals, as was the case in the present study. At the steady spike frequency we chose $(26.5$ spikes $/ \mathrm{sec})$, the steady firing rates of $\mathrm{L} 2 / 3$ and slender L 5 cells were approximately one-eighth and one-fifth, respectively, of the initial rates. Although the firing rate of our cells was relatively stable by the end of the 400-msec current pulses used in this study, we cannot exclude the possibility that a further phase of spike frequency adaptation would have been revealed by longer pulses (Koike et al., 1970; Gustafsson et al., 1978; Stafstrom et al., 1984a). With the exception of the characteristic bursts of thick L5 cells, the firing frequency for the first interspike interval was always greater than for subsequent intervals, regardless of current strength. We never saw the transient acceleration of firing frequency that has been reported for some pyramidal tract cells in vivo (Koike et al., 1970) and sensorimotor cortical cells in vitro (Stafstrom et al., 1984a).

Many different conductances will be active at the membrane potentials traversed during repetitive firing, so $\mathrm{f} / \mathrm{I}$ relationships and spike frequency adaptation are likely to be influenced by several different inward and outward currents. A persistent sodium current, and calcium-sensitive potassium currents underlying the spike after-hyperpolarizations, have been implicated in controlling the steepness of $\mathrm{f} / \mathrm{I}$ relationships in L5 neurons of cat sensorimotor cortex (Stafstrom et al., 1982; Schwindt et al., 1988c). Several different conductances probably contribute to spike frequency adaptation in neocortical neurons (Spain et al., 1987; Schwindt et al., 1988b, 1989; Foehring et al., 1989). Since some of these are sensitive to neurotransmitter agonists, it is possible that synaptic input could modulate repetitive firing properties.

\section{Conclusions}

On morphological grounds we have recognized 3 classes of pyramidal neurons in layers $2 / 3$ and 5 of rat visual cortex. From a comparison of our morphological findings with studies in which projection targets were identified by retrograde labeling or antidromic stimulation (Schofield et al., 1987; Hallman et al., 1988; Hübener and Bolz, 1988), it seems likely that thick L5 cells project to the superior colliculus or pons (or both), whereas at least some of the slender L 5 cells may project through the callosum to contralateral cortex. The differences in dendritic morphology will influence the spectrum of synaptic inputs available to each kind of cell, and we have also shown that the 3 classes of neuron have different subthreshold and suprathreshold intrinsic membrane properties. Together these attributes will play a large part in determining the input-output relations of the neurons. Although we do not yet know how these features relate to the functional role of cach kind of neuron, the evidence for correlations between dendritic morphology, projection target, and electrophysiological properties suggests that cortical neurons are tailored to receive particular information and process it in specific ways appropriate to their function.

\section{References}

Adams PR, Galvan M (1986) Voltage-dependent currents of vertebrate neurons and their role in membrane excitability. In: Advances in neurology, Vol 44 (Delgado-Escueta AV, Ward AA, Woodbury DM, Porter RJ, eds), pp 137-171. New York: Raven.

Adams PR, Brown DA, Constanti A (1982) M-currents and other petassium currents in bullfrog sympathetic neurones. J Physiol 330: 537-572.

Andersen P, Storm J, Wheal HV (1987) Thresholds of action potentials evoked by synapses on the dendrites of pyramidal cells in the rat hippocampus in vitro. J Physiol 383:509-526.

Arbas EA, Calabrese RL (1987) Ionic conductances underlying the activity of interneurons that control heartbeat in the medicinal leech. J Neurosci 7:3945-3952.

Artola A, Singer W (1987) Long-term potentiation and NMDA receptors in rat visual cortex. Nature 330:649-652.

Avoli M, Olivier A (1989) Electrophysiological properties and synaptic responses in the deep layers of the human epileptogenic neocortex in vitro. J Neurophysiol 61:589-606.

Bindman LJ, Meyer T, Prince CA (1988) Comparison of the electrical properties of neocortical neurones in slices in vitro and in the anaesthetized rat. Exp Brain Res 69:489-496.

Brown DA (1988) M currents. In: Ion channels, Vol 1 (Narahashi T, ed), pp 55-94. New York: Plenum.

Calvin WH, Sypert GW (1976) Fast and slow pyramidal tract neurons: an intracellular analysis of their contrasting repetitive firing properties in the cat. J Neurophysiol 39:420-434.

Connors BW, Gutnick MJ (1984) Cellular mechanisms of neocortical epileptogenesis in an acute experimental model. In: Electrophysiology of epilepsy (Schwartzkroin PA, Wheal HV, eds), pp 79-105. London: Academic.

Connors BW, Kriegstein AR (1986) Cellular physiology of the turtle visual cortex: distinctive properties of pyramidal and stellate neurons. J Neurosci 6:164-177.

Connors BW, Gutnick MJ, Prince DA (1982) Electrophysiological properties of neocortical neurons in vitro. J Neurophysiol 48:13021320. 
Connors BW, Malenka RC, Silva LR (1988) Two inhibitory postsynaptic potentials, and $\mathrm{GABA}_{\mathrm{A}}$ and $\mathrm{GABA}_{\mathrm{B}}$ receptor-mediated responses in neocortex of rat and cat. J Physiol 406:443-468.

Constanti A, Galvan M (1983a) Fast inward-rectifying current accounts for anomalous rectification in olfactory cortex neurones. $J$ Physiol 385:153-178.

Constanti A, Galvan M (1983b) M-current in voltage-clamped olfactory cortex neurones. Neurosci Lett 39:65-70.

Crepel F, Penit-Soria J (1986) Inward rectification and low threshold calcium conductance in rat cerebellar Purkinje cells. An in vitro study. J Physiol 372:1-23.

Deisz RA (1988) The current components of intrinsic bursting neurones of the guinea pig neocortex. Eur J Physiol 41 1(suppl 1):R126.

Deisz RA, Prince DA (1987) Effect of D890 on membrane properties of neocortical neurons. Brain Res 422:63-73.

Deschênes M, Labelle A, Landry P (1979) Morphological characterization of slow and fast pyramidal tract cells in the cat. Brain Res $178: 251-274$.

Deschênes M, Paradis M, Roy JP, Steriade M (1984) Electrophysiology of neurons in lateral thalamic nuclei in cat: resting properties and burst discharges. J Neurophysiol 51:1196-1219.

Fleshman JW, Segev I, Burke RE (1988) Electrotonic architecture of type-identified $\alpha$-motoneurons in the cat spinal cord. J Neurophysiol 60:60-85.

Foehring RC, Schwindı PC, Crill WE (1989) Norepinephrine selectively reduccs slow $\mathrm{Ca}^{2}{ }^{+}$- and $\mathrm{Na}{ }^{-}$-mediated $\mathrm{K}^{+}$currents in cat ncocortical neurons. J Neurophysiol 61:245-256.

Franz P, Galvan M, Constanti A (1986) Calcium-dependent action potentials and associated inward currents in guinea-pig neocortical neurons in vitro. Brain Res 366:262-271.

Friedman A, Gutnick MJ (1987) Low-threshold calcium electrogenesis in neocortical neurons. Neurosci Lett 81:117-122.

Friedman A, Gutnick MJ (1989) Intracellular calcium and control of burst generation in neurons of guinea-pig neocortex in vitro. Eur J Neurosci 1:374-381

Gamble E, Koch C (1987) The dynamics of free calcium in dendritic spines in response to repetitive synaptic input. Science 236:13111315.

Gilbert CD, Wiesel TN (1979) Morphology and intracortical projections of functionally characterised ncurones in the cat visual cortex. Nature 280:120-125.

Griffith WH (1988) Membrane properties of cell types within guinea pig basal forebrain nuclei in vitro. J Neurophysiol 59:1590-1612.

Gustafsson B, Pinter MJ (1984) Relations among passive electrical properties of lumbar $\alpha$-motoneurones of the cat. J Physiol 356:401431.

Gustafsson B. Wigström H (1981) Shape of frequency-current curves in CA1 pyramidal cells in the hippocampus. Brain Res 223:417-421.

Gustafsson B, Lindström S, Zangger P (1978) Firing behaviour of dorsal spinocerebellar tract neurones. J Physiol 275:321-343.

Gutnick MJ, Friedman A (1986) Synaptic and intrinsic mechanisms of synchronization and epileptogenesis in the neocortex. In: Calcium electrogenesis and neuronal functioning (Heinemann U, Klee M, Neher E, Singer W, eds), pp 327-335. Bcrlin: Springcr-Vcrlag.

Hablitz JJ (1986) Mechanisms regulating synchronization of hippocampal epileptiform activity. In: Calcium electrogenesis and neuronal functioning (Heinemann U, Klee M, Neher E, Singer W, eds), pp 337344. Berlin: Springer-Verlag.

Halliwell JV (1986) M-current in human neocortical neurones. Neurosci Lett 67:1-6.

Halliwell JV, Adams PR (1982) Voltage-clamp analysis of muscarinic excitation in hippocampal neurons. Brain Res 250:71-92.

Hallman LE, Schofield BR, Lin C-S (1988) Dendritic morphology and axon collaterals of corticotectal, corticopontine, and callosal neurons in layer $\mathrm{V}$ of primary visual cortex of the hooded rat. J Comp Neurol 272:149-160.

Hamada I, Sakai M, Kubota K (1981) Morphological differences between fast and slow pyramidal tract ncurons in the monkcy motor cortex as revealed by intracellular injection of horseradish peroxidase by pressure. Neurosci Lett 22:233-238.

Hounsgaard J, Midtgaard J (1988) Intrinsic determinants of firing pattern in Purkinje cells of the turtle cerebellum in vitro. J Physiol 402:731-749.

Hübener M, BolzJ (1988) Morphology of identified projection neurons in layer 5 of rat visual cortex. Neurosci Lett 94:76-81.
Huguenard JR, Hamill OP, Prince DA (1988) Developmental changes in $\mathrm{Na}^{+}$conductances in rat neocortical neurons: appearance of a slowly inactivating component. J Neurophysiol 59:778-795.

lansek R, Redman SJ (1973) An analysis of the cable properties of spinal motoneurones using a brief intracellular current pulse. J Physiol 234:613-636

Ito M, Oshima T (1965) Electrical behaviour of the motoneurone membrane during intracellularly applied current steps. J Physiol 180: $607-635$.

Jodkowski JS, Viana F, Dick TE, Berger AJ (1988) Repetitive firing properties of phrenic motoneurons in the cat. J Neurophysiol 60:687702.

Johnston D, Hablitz JJ, Wilson WA (1980) Voltage clamp discloses slow inward current in hippocampal burst-firing neurones. Nature 286:391-393.

Jones RSG, Heinemann U (1988) Synaptic and intrinsic responses of medial entorhinal cortical cells in normal and magnesium-free medium in vitro. J Neurophysiol 59:1476-1496.

Kernell D (1965) High-frequency repetitive firing of cat lumbosacral motoneurones stimulated by long-lasting injected currents. Acta Physiol Scand 65:74-86.

Koike H, Mano N, Okada Y, Oshima T (1970) Repetitive impulses generated in fast and slow pyramidal tract cells by intracellularly applied current steps. Exp Brain Res 11:263-281.

Konnerth A, Lux HD, Heinemann U (1986) Ionic properties of burst generation in hippocampal pyramidal cell somata in vitro. In: Calcium electrogenesis and neuronal functioning (Heinemann U, Klee M, Neher E, Singer W, eds), pp 368-374. Berlin: Springer-Verlag.

Lanthorn T, Storm J, Andersen P (1984) Current-to-frequency transduction in CAI hippocampal pyramidal cells: slow prepotentials dominate the primary range firing. Exp Brain Res 53:431-443.

Larkman A, Mason A (1990) Correlations between morphology and electrophysiology of pyramidal neurons in slices of rat visual cortex. I. Establishment of cell classes. J Neurosci 10:1407-1414.

Larkman AU, Mason A, Blakemore C (1988) The in vitro slice preparation for combined morphological and electrophysiological studics of rat visual cortex. Neurosci Res 6:1-19.

Lasater EM (1988) Membrane currents of retinal bipolar cells in culture. J Neurophysiol 60:1460-1480.

Llinás R, Jahnsen H (1982) Electrophysiology of mammalian thalamic neurones in vitro. Nature 297:406-408.

Llinás R, Sugimori M (1984) Simultaneous intracellular somatic and dendritic recording from Purkinje cells in vitro: dynamic soma-dendritic coupling. Soc Neurosci Abstr 10:659.

Lopez-Barneo J, Llinás R (1988) Electrophysiology of mammalian tectal neurons in vitro. I. Transient ionic conductances. J Neurophysiol 60:853-868.

Martin KAC, Whitteridge D (1984) Form, function and intracortical projections of spiny neurones in the striate visual cortex of the cat. J Physiol 353:463-504.

Mayer MM, Westbrook GL (1983) A voltage-clamp analysis of inward (anomalous) rectification in mouse spinal sensory ganglion neurones. J Physiol 340:19-45.

McCormick DA, Prince DA (1986) Mechanisms of action of acctylcholine in the guinea-pig cerebral cortex in vitro. J Physiol 375:169 194

McCormick DA, Prince DA (1987) Post-natal development of electrophysiological properties of rat cerebral cortical pyramidal neurones. J Physiol 393:743-762.

McCormick DA, Prince DA (1988) Noradrenergic modulation of firing pattern in guinea pig and cat thalamic neurons, in vitro. J Neurophysiol 59:978-996.

McCormick DA, Connors BW, Lighthall JW, Prince DA (1985) Comparative electrophysiology of pyramidal and sparsely spiny stellate neurons of the neocortex. J Neurophysiol 54:782-806.

Miller MW (1988) Maturation of rat visual cortex. IV. The generation, migration, morphogenesis, and connectivity of atypically oriented pyramidal neurons. J Comp Neurol 274:387-405.

Montoro RJ, López-Barneo J, Jassik-Gerschenfeld D (1988) Differential burst firing modes in neurons of the mammalian visual cortex in vitro. Brain Res 460:168-172.

Ogawa $\mathrm{T}$, Ito $\mathrm{S}$, Kato $\mathrm{H}$ (1981) Membrane characteristics of visual cortical neurons in in vitro slices. Brain Res 226:315-319.

Osmanovic SA, Shefner SA (1987) Anomalous rectification in rat locus coeruleus neurons. Brain Res 417:161-166. 
Parnavelas JG, Burne RA, Lin C-S (1983) Distribution and morphology of functionally identified neurons in the visual cortex of the rat. Brain Res 261:21-29.

Penit-Soria J, Audinat E, Crepel F (1987) Excitation of rat prefrontal cortical neurons by dopamine: an in vitro electrophysiological study. Brain Res 425:263-274.

Peters A (1987) Number of neurons and synapses in primary visual cortex. In: Cerebral cortex, Vol 6 (Jones EG, Peters A, eds), pp $267-$ 294. New York: Plenum.

Peters A, Jones EG, eds (1985) Cerebral cortex, Vol 3. New York: Plenum.

Prince DA, Connors BW (1986) Mechanisms of interictal epileptogenesis. In: Advances in neurology, Vol 44 (Delgado-Escueta AV, Ward AA, Woodbury DM, Porter RJ, eds), pp 275-299. New York: Raven.

Rall W (1969) Time constants and electrotonic length of membrane cylinders and neurons. Biophysical J 9:1483-1508.

Rose D, Dobson VG, eds (1985) Models of the visual cortex. Chichester: Wiley.

Rose PK, Dagum A (1988) Nonequivalent cylinder models of neurons: interpretation of voltage transients generated by somatic current injection. J Neurophysiol 60:125-148.

Rose PK, Vanner S.J (1988) Differences in somatic and dendritic specific membrane resistivity of spinal motoneurons: an electrophysiological study of neck and shoulder motoneurons in the cat. J Neurophysiol 60:149-166.

Scharfman HE, Sarvey JM (1987) Responses to GABA recorded from identified rat visual cortical neurones. Neuroscience 23:407-422.

Schofield BR, Hallman LE, Lin C-S (1987) Morphology of corticotectal cells in the primary visual cortex of hooded rats. J Comp Neurol 261:85-97.

Schwindt PC (1973) Membrane-potential trajectories underlying motoneuron rhythmic firing at high rates. J Neurophysiol 36:434-449.

Schwindt PC, Spain WJ, Crill WE (1988a) Influence of anomalous rectifier activation on afterhyperpolarizations of neurons from cat sensorimotor cortex in vitro. J Neurophysiol 59:468-481.

Schwindt PC, Spain WJ, Foehring RC, Chubb MC, Crill WE (1988b) Slow conductances in neurons from cat sensorimotor cortex in vitro and their role in slow excitability changes. J Neurophysiol 59:450 467.

Schwindt PC, Spain WJ, Foehring RC, Stafstrom CE, Chubb MC, Crill WE (1988c) Multiple potassium conductances and their functions in neurons from cat sensorimotor cortex in vitro. J Neurophysiol 59: 424-449.

Schwindt PC, Spain WJ, Crill WE (1989) Long-lasting reduction of excitability by a sodium-dependent potassium current in cat neocortical neurons. J Neurophysiol 61:233-244.

Spain WJ, Schwindt PC, Crill WE (1987) Anomalous rectification in neurons from cat sensorimotor cortex in vitro. J Neurophysiol 57: 1555-1576.
Stafstrom CE, Schwindt PC, Crill WE (1982) Ncgative slope conductance due to a persistent subthreshold sodium current in cat neocortical neurons in vitro. Brain Res 236:221-226.

Stafstrom CE, Schwindt PC, Crill WE (1984a) Repetitive firing in layer $\mathrm{V}$ neurons from cat neocortex in vitro. J Neurophysiol 52:264277.

Stafstrom CE, Schwindt PC, Flatman JA, Crill WE (1984b) Properties of subthreshold response and action potential recorded in layer $\mathrm{V}$ neurons from cat sensorimotor cortex in vitro. $\mathbf{J}$ Neurophysiol 52: 244-263.

Stafstrom CE, Schwindt PC, Chubb MC, Crill WE (1985) Properties of persistent sodium conductance and calcium conductance of layer $\mathrm{V}$ neurons from cat sensorimotor cortex in vitro. J Neurophysiol 53 : 153-170.

Stcriade M, Llinás RR (1988) The functional states of the thalamus and the associated neuronal interplay. Physiol Rev 68:649-742.

Storm JF (1988) Temporal integration by a slowly inactivating $\mathrm{K}^{+}$ current in hippocampal neurons. Nature 336:379-381.

Sutor B, Zieglgänsberger W (1987) A low-voltage activated, transient calcium current is responsible for the time-dependent depolarizing inward rectification of rat neocortical neurons in vitro. Pfluegers Arch 410:102-111.

Thomson AM (1986) A magnesium-sensitive post-synaptic potential in rat cerebral cortex resembles neuronal responses to $N$-methylaspartate. J Physiol 370:531-549.

Thomson AM, Girdlestone D, West DC (1988) Voltage-dependent currents prolong single-axon postsynaptic potentials in layer III pyramidal neurons in rat neocortical slices. J Neurophysiol 60:18961907.

Williams JT, Colmers WF, Pan ZZ (1988) Voltage- and ligand-activated inwardly rectifying currents in dorsal raphe neurons in vitro. $\mathrm{J}$ Neurosci 8:3499-3506.

Wong RKS, Prince DA (1978) Participation of calcium spikes during intrinsic burst firing in hippocampal neurons. Brain Res 159:385390.

Wong RKS, Prince DA (1981) Afterpotential generation in hippocampal pyramidal cells. J Neurophysiol 45:86-97.

Yarom Y, Llinás R (1987) Long-term modifiability of anomalous and delayed rectification in guinea pig inferior olivary neurons. J Neurosci 7:1166-1177.

Yoshii K, Moore LE, Christensen BN (1988) Effect of subthreshold voltage-dependent conductances on the transfer function of branched excitablc cells and the conduction of synaptic potentials. J Ncurophysiol 59:706-716.

Zengel JE, Reid SA, Sypert GW, Munson JB (1985) Membrane electrical properties and prediction of motor-unit type of medial gastrocnemius motoneurons in the cat. J Neurophysiol 53:1323-1344.

Zona C, Pirrone G, Avoli M, Dichter M (1988) Delayed and fast transient potassium currents in rat neocortical neurons in cell culture. Neurosci Lett 94:285-290. 